\title{
Growth in a Cross-Section of Cities: Location, Increasing Returns or Random Growth?
}

\author{
Rafael González-Val ${ }^{\mathrm{a}}$ \\ Jose Olmo ${ }^{\mathrm{b}}$ \\ ${ }^{a}$ Universidad de Zaragoza \& Institut d'Economia de Barcelona (IEB) \\ ${ }^{b}$ University of Southampton
}

\begin{abstract}
This article analyses empirically the main existing theories on income and population city growth: increasing returns to scale, locational fundamentals and random growth. To do this we consider a large database of urban, climatological and macroeconomic data from 1,173 US cities observed in 1990 and 2000. The econometric model is robust to the presence of spatial effects. Our analysis shows the existence of increasing returns and two distinct equilibria in per-capita income and population growth. We also find important differences in the structure of productive activity, unemployment rates and geographical location between cities in low-income and high-income regimes.
\end{abstract}

Keywords: threshold tests, locational fundamentals, multiple equilibria, random growth JEL Classification Codes: C12, C13, C33, O1, R0, R11 


\section{Introduction}

There are differences in the growth rates of cities. It is evident that some cities (or regions) are more productive than others, or attract more population, depending on certain circumstances that vary over time. Several explanations have been proposed to try to explain these differentiated behaviours. Following Davis and Weinstein (2002), these theoretical explanations can be grouped into three main theories: the existence of increasing returns to scale, the importance of locational fundamentals and the absence of both (random growth).

Each theory has different implications for the understanding of city growth over recent decades. Thus, the existence of increasing returns suggests the presence of endogenous mechanisms in city growth that lead to multiple equilibria depending on initial conditions on income or population. Seminal articles discussing the endogenous character of city growth and proposing theoretical models of urban growth are Fujita (1976), Palivos and Wang (1996), Eaton and Eckstein (1997) and Black and Henderson (1999). In contrast, there is a body of literature influenced by the belief that city growth is driven by exogenous characteristics that help to shape the landscape of opportunities for their inhabitants prompting economic and population growth. This theory implies the existence of conditional convergence towards different equilibria that in contrast to the previous case is driven by exogenous factors linked to geography. According to this theory, the presence of a natural harbour, a specific climate or access to the sea, among many other socio-economic and locational characteristics, can determine cities' income and population. A third theory postulates that economic growth cannot be attributed to measurable endogenous or exogenous characteristics but instead to the occurrence of random events that act as drivers of economic activity over time.

Empirical economists on urban economics and economic geography have debated over the suitability of each of these theories for different periods and countries, see for example, Davis and Weinstein (2002) or Bosker et al. (2008), and the literature review in the next section. The availability of census data and the development of sophisticated econometric methods for modelling nonlinearities in time series and cross-sectional analysis have made possible to formally test statistically to what extent each theory helps to predict city growth. 
The aim of this paper is to disentangle between these theories by determining the contribution that each theory has on explaining income and population growth. This is done by exploiting a large database of urban, climatological and macroeconomic data from 1,173 US cities observed in 1990 and 2000. More specifically, the contribution of this paper is to develop an econometric specification for growth predictive regressions sufficiently general to nest each of the above theories on city growth as particular cases. By doing so we can perform different likelihood ratio tests to determine what theory is better suited to describing the data on US cities. One of these statistical tests aims to capture the potential of endogenous growth in the form of increasing returns to scale. This is done by adapting the threshold nonlinearity tests developed in Hansen $(1996,1997)$ to our cross-sectional setting.

The econometric specification proposed for the analysis of the above theories is founded on a theoretical model of growth that expands the seminal contributions of Solow (1956) and Diamond (1965) to the nonlinear case. Following the contributions of Fingleton and López-Bazo (2006) and Le Gallo et al. (2003), our theoretical model also accommodates the presence of spatial effects in economic activity. In contrast to Fingleton and López-Bazo (2006) that focuses on the presence of across-region externalities due to knowledge diffusion, we incorporate spatial components in the growth model to describe neighbouring effects due to spillovers across neighbouring cities exposed to the same shocks. Following a similar approach to López-Bazo et al (2004), our empirical economic growth specifications also have their basis on neoclassical economic growth theory. In our case, our models for explaining economic and population growth gravitate around the concept of multiple equilibria.

Two distinct models are consistent with the idea of multiple equilibria. The first is the notion of a poverty trap. A poverty trap arises when poor individuals, cities or countries are faced with two distinct equilibria, one below the poverty trap and one above it. Individuals with sufficiently low income or asset endowments are trapped in the poor equilibrium, and small improvements are not enough to escape the forces bringing them back to this level. In this conceptualization of multiple equilibria, individuals are classified according to some level of income that is defined by a threshold value above which they should be able to escape poverty. This idea rests on the existence of increasing returns to 
income and productivity. In the second model, individuals can be sorted into two groups depending on their intrinsic socio-economic and locational characteristics: the first group corresponds to low-income levels and the second group to high-income levels. This model corresponds to the concept of conditional convergence, where different individuals converge to different levels depending on their fundamentals.

Our results provide mixed evidence on the importance of increasing returns and locational fundamentals for predicting economic and population growth. On one hand, our statistical threshold nonlinearity test finds empirical evidence of threshold nonlinearities suggesting the existence of different equilibria that depend on the initial levels of income and population. On the other hand, the statistical measures gauging the explanatory power of the econometric specification, such as the coefficient of determination, suggest that the inclusion of exogenous variables, locational fundamentals, significantly improve the fit of the empirical model highlighting the major role of these variables in explaining the observed levels of income and population across cities in the US. The spatial component of our empirical specification is also relevant for describing neighbouring effects on growth across cities. These empirical findings suggest that multiple equilibria in city growth is mainly determined by locational fundamentals and corresponds to conditional convergence in equilibrium. Nevertheless, the existence of increasing returns in economic and population growth suggest that cities sharing the same values of locational fundamentals will converge to different equilibria if their initial levels of income lie on different regions of the nonlinear threshold empirical specification.

The article is structured as follows. The next section reviews the related literature. Section 3 introduces a theoretical specification of growth models that accommodates the presence of endogenous threshold nonlinearities of capital accumulation on economic growth. The section also discusses a simple extension of this model to describe population growth in the spirit of the seminal works of Glaeser et al. (1995) and Glaeser (2000). Section 4 sets out the econometric framework and discusses the different hypothesis tests of interest. Section 5 discusses the empirical results for a database containing 1,173 US cities and the last Section concludes. An appendix contains data sources and collects the tables. 


\section{Related literature}

Davis and Weinstein (2002) group the traditional theoretical explanations of urban growth into three main theories: the existence of increasing returns to scale, the importance of locational fundamentals and the absence of both (random growth).

The first theory is supported by the theoretical models of the New Economic Geography (NEG). These models often display nonlinear behaviours and multiple equilibria as a consequence of their basic assumptions (mobile factors, transport costs, centrifugal and centripetal forces, etc.), which are very different from the classic framework. The literature on urban increasing returns, also known as agglomeration economies, is wide (see the meta-analysis by Melo et al., 2009). The traditional Marshallian sources of external economies of scale are labour market pooling, input sharing and knowledge spillovers. Duranton and Puga (2004) provide an alternative perspective, namely that agglomeration economies could be driven by sharing, matching or learning mechanisms. In addition, there is also evidence that other factors contribute to agglomeration, such as home market effects, consumption opportunities and rent-seeking (see the survey by Rosenthal and Strange, 2004).

In the economic literature, locational fundamentals are considered to be geographical factors linked to the physical landscape, such as temperature, rainfall, access to the sea, the presence of natural resources or the availability of arable land. Random growth models usually assume that these characteristics are randomly distributed across space, but actually they are not. From a physical geography perspective, factors such as mineral resources and nice weather are clearly concentrated in certain areas. Several studies find a significant influence of these characteristics on the development of some particular regions. For example, the nearby deposits of coal, iron ore and limestone as well as the extensive network of natural waterways and deep water sea and river ports contributed to the development of the US manufacturing belt in the Upper Midwest and North-east regions (Berry and Kasarda, 1977). Fernihough and O’Rourke (2014) also find that coal had a strong influence on city population; according to their estimates coal explains at least 60\% of the growth in European city populations from 1750 to 1900.

Nevertheless, although locational fundamentals may have played a crucial role in 
early settlements, one would expect that their influence decreases over time. However, empirical studies demonstrate that their important influence in determining agglomeration remains. For the case of the United States, Ellison and Glaeser (1999) state that natural advantages, such as the presence of a natural harbour or a particular climate, can explain about $20 \%$ of the observed geographic concentration. Glaeser and Shapiro (2003) find that in the 1990s people moved to warmer, dryer places, while Rappaport (2007) explains that a large proportion of weather-related movement seems to be driven by an increased valuation of nice weather as a consumption amenity.

Random growth theories are based on stochastic growth processes and probabilistic models. The most important models are those presented by Champernowne (1953), Simon (1955) and, more recently, Gabaix (1999). In the case of population growth, these models are able to reproduce an empirical regularity well-known in urban economics: Gibrat's law (or the law of proportionate growth). For the case of the US, several works statistically accept the fulfilment of Gibrat's law, whether at the level of places (Eeckhout, 2004; González-Val, 2010) or metropolitan areas (Ioannides and Overman, 2003). In contrast to these studies, Black and Henderson (2003) reject Gibrat's law, using a different dataset of metro areas in the US. Michaels et al. (2012) use data from Minor Civil Divisions and counties to track the evolution of populations across both rural and urban areas in the US from 1880 to 2000, finding that Gibrat's law is a reasonable approximation for population growth only for the largest units.

However, recent studies argue that empirically random growth can only hold as a long-run average; Gabaix and Ioannides (2004) point out that "the casual impression of the authors is that in some decades, large cities grow faster than small cities, but in other decades, small cities grow faster.” This size-dependent growth would rebut random growth in the short-term, but random growth theory would still be important from a long-term perspective, because the influence of other factors such as locational fundamentals and increasing returns may change (or even disappear) over time. A unifying approach to justify random growth models could be a combination of weak size-dependence and decaying impact of locational fundamentals over time (because of advances in transportation and communication technology) or random changes in the importance of each fundamentals (e.g. in the case of weather). 
While there are many studies of each of these theories, the literature on alternative approaches is scant; only Davis and Weinstein (2002, 2008) and Bloom et al. (2003) adopt such a broad perspective. The first authors support a hybrid theory in which locational fundamentals establish the spatial pattern of relative regional densities, but increasing returns help determine the degree of spatial differentiation in Japanese cities. Similarly, Bloom et al. (2003) study the influence of climatological and geographical variables on growth at a country level. These authors develop a Markov regime-switching model to analyse whether locational fundamentals have additional explanatory power to describe per-capita income growth compared with nonlinear models based on lagged per-capita income. Finally, Davis and Weinstein (2008) develop a threshold regression framework for distinguishing the hypothesis of unique versus multiple equilibria and apply it to the Allied bombing of Japan during World War II, finding evidence against multiple equilibria. Bosker et al. (2007) replicate this analysis for the bombing of Germany during World War II and their results support a model with two stable equilibria.

\section{Convergence equations for income and population}

The structural factors that contribute to city income include consumption, investment, trade and local government expenditure. All these variables depend on a set of socioeconomic and geographical variables that determine the economic size of a city. These variables include literacy variables such as schooling, socioeconomic variables such as productive structure or unemployment rate and geographical and environmental variables such as temperature or climate. Our interest is in studying the influence of these explanatory variables on aggregate measures of city income and population growth.

Among the several potential indicators for economic activity we choose two different dependent variables at the city level: population and per-capita income. Both of them are second nature variables closely linked (higher per-capita income stimulates migration), but they give different information. Although the two variables are assumed to capture many agglomeration economies such as informational spillovers or labour market economies (Roos, 2005), population is a measure of urban concentration and a proxy for urban amenities and potential congestion costs (Melo et al., 2009), while income is a more direct measure of city's productivity. Glaeser et al. (1995) discuss both measures of city size; population growth captures the extent to which cities are becoming increasingly 
attractive habitats and labour markets across cities, while income growth captures some portion of productivity growth but it also captures declines in quality of life. Empirical studies usually consider only one of them; but there are exceptions: Glaeser et al. (1995), Roos (2005) and González-Val (2014). Glaeser et al. (1995) and González-Val (2014) analyze the influence of a set of initial city characteristics on both population and income growth in US cities, and Roos (2005) considers these two second-nature variables and develops a stepwise procedure to infer the unobservable effect of first nature for Germany. Chasco et al. (2012) adapt this framework to allow for spatial effects.

The aim of our study is to provide a formal analysis of growth for each of these variables (per-capita income and population). In order to provide a meaningful econometric specification it is convenient to set the microfoundations of city income and population. To do this, we build on two different neoclassical models of economic growth. More specifically, we analyse growth in per-capita income using a framework consistent with the existence of poverty traps. Similarly, our analysis of city population builds on the seminal contributions of Glaeser et al. (1995) and Glaeser (2000). These models are extended in this paper to accommodate the presence of nonlinearities in the growth equation and the potential of spatial effects.

To motivate the existence of a poverty trap in city income growth we follow Barro and Sala-i-Martin (2004, ch.1) exposition of a Solow-Swan type model with a generic city that has access to a traditional (A) and a modern (B) technology. Each technology is represented by a Cobb-Douglas production function with two factors of production (labour and capital) and constant returns to scale. In per capita terms, these production functions are $Y_{A}=A K^{\alpha}$ and $Y_{B}=B K^{\beta}$ where $Y$ is a measure of per capita city income, $K$ is the per capita capital stock and $\alpha, \beta \in(0,1) ; A, B>0$ are the parameters capturing the contribution of technology to the production function. Different from Barro and Sala-i-Martin (2004, ch.1) we allow for the possibility of $\alpha \neq \beta$, that is, distinct capital elasticities, and, for simplicity, assume that $\alpha<\beta$ to ensure non-reversibility.

This nonlinear specification of city income is extended to reflect the effect of locational fundamentals. The relevant production functions accommodating these effects are $Y_{A}=A K^{\alpha} X^{\gamma}$ and $Y_{B}=B K^{\beta} X^{\gamma}$, with $X^{\gamma}=X_{1}^{\gamma_{1}} \cdots X_{n}^{\gamma_{n}}$ denoting the vector of 
locational fundamentals; $X=\left(X_{1}, \cdots, X_{n}\right)^{\prime}$ and $\gamma=\left(\gamma_{1}, \cdots, \gamma_{n}\right)^{\prime}$. After simple algebra, the log-linearized envelope production function can be expressed as the combination of the above functions as

$$
y=a+\left\{\begin{array}{l}
\alpha k+\gamma^{\prime} x, \text { if } k \leq \bar{k} \\
\beta k+\gamma^{\prime} x, \text { if } k>\bar{k}
\end{array}\right.
$$

where for notational convenience we use $x=\ln X$. More compactly, we have

$$
y=a+\left(\alpha k+\gamma^{\prime} x\right) I(k \leq \bar{k})+\left(\beta k+\gamma^{\prime} x\right) I(k>\bar{k})
$$

with I(.) an indicator variable taking the value of one when the argument is true and zero otherwise; $\bar{k}$ denotes the threshold characterizing the nonlinearities in the growth equation.

The derivation of the growth equation describing transitional dynamics is standard in the growth literature (Mankiw et al., 1992; Barro and Sala-i-Martin, 1992). A detailed derivation of the growth equation corresponding to the Cobb-Douglas production function described above where externalities across economies are included in the technology of production is offered in the appendix of Fingleton and López-Bazo (2006). After suitable modification of the algebra to accommodate the above piecewise linear specification, the corresponding empirical specification of the growth equation is in our setting equal to

$$
\Delta y_{i}=\gamma_{0}+\gamma_{11} y_{i o} I\left(y_{i o} \leq u\right)+\gamma_{12} y_{i o} I\left(y_{i o}>u\right)+\gamma_{2}{ }^{\prime} x_{i o},
$$

where $\Delta y_{i}=y_{i f}-y_{i o}$ is the growth variable that is measured as the difference of the terminal and initial values of log per-capita income, $y_{i f}$ and $y_{i o}$, respectively; $x_{i o}$ is a vector of socioeconomic and geographical indicators; $u$ is the threshold value corresponding to lagged income. The parameters gauging the extent of increasing returns on per-capita income are $\gamma_{11}$ and $\gamma_{12}$. The parameter $\gamma_{2}$ determines the effect of the locational fundamentals in the growth equation. This model reflects two different types of multiple equilibria: an equilibrium arising from nonlinear endogenous growth and characterised by the presence of increasing returns, and another equilibrium that reflects conditional convergence and characterized by the values of the locational fundamentals.

To describe the growth equation for population we extend the approach put forward in Glaeser et al. (1995) and further developed in Glaeser (2000). We assume that cities are in a spatial equilibrium where individual utility and the returns to capital are equalized 
across space. Each city produces according to the production functions $Y_{A}$ and $Y_{B}$ introduced before. Thus, the returns to capital (equal to the marginal product) are different depending on the type of technology: $r_{A}=\alpha A K^{\alpha-1} X^{\gamma}$ and $r_{B}=\beta A K^{\alpha-1} X^{\gamma}$, respectively. Utility equals $\frac{C W}{P}$, where $C$ is a city-level consumption amenity index, $W$ represents city-level wages, and $P$ describes city-level prices. To add city population to the model, it is assumed that the total labour in the city is equal to $z$ times total city population, with $0<z \leq 1$, representing $(1-z)$ the share of nonworking population in the city. In the case that production is the same across technological levels $\alpha$ and $\beta$, giving rise to a linear specification of per-capita income, these equations produce the following equality ${ }^{1}$

$$
\Delta l_{i}=\eta_{0}+\eta_{1} l_{i o}+\eta_{2}^{\prime} x_{i o}
$$

with $\Delta l_{i}=l_{i f}-l_{i o}$ being the difference of the terminal and initial values of log population and $\varepsilon_{i}^{*}$ a mean zero iid error term with constant variance; $\eta_{0}$ is the intercept and $\eta_{1}$ and $\eta_{2}$ are the parameters that describe the marginal effect of the explanatory variables. $x_{i o}$ is again a vector of city-characteristics. This is a model of spatial equilibrium similar to the Roback (1982) model, where the relationship between population growth and initial characteristics is determined by changes in demand for some aspects of the city's initial endowment in production or consumption, or by the effect of this initial characteristic on productivity growth. After suitable algebra, it can be shown that the threshold nonlinear version of the model describing population growth is

$$
\Delta l_{i}=\eta_{0}+\eta_{11} l_{i o} I\left(l_{i o} \leq v\right)+\eta_{12} l_{i o} I\left(l_{i o}>v\right)+\eta_{2}^{\prime} x_{i o} .
$$

As in the previous case, this model also reflects two different types of multiple equilibria: an equilibrium arising from the presence of increasing returns and another equilibrium characterized by locational fundamentals and leading to conditional convergence.

However, the existence of a spatial equilibrium does not necessarily imply the same equilibrium city size and thus growth convergence across cities. ${ }^{2}$ In Henderson's (1974) seminal system of cities model (and in many of the subsequent models) all cities are fully

\footnotetext{
${ }^{1}$ We use simpler notation, but this equation is equivalent to Eq. (2.7) and Eq. (1') in Glaeser et al. (1995) and Glaeser (2000), respectively.

${ }^{2}$ We acknowledge one anonymous referee for suggesting this point.
} 
specialised in equilibrium and only the cities with the same specialisation must be of the same size (Combes et al., 2005). Nevertheless, other theoretical frameworks combine diversified and specialized cities (Duranton and Puga, 2001) and in equilibrium all the cities of the same type are of the same size.

\section{Econometric methodology}

\subsection{Estimation}

The different specifications of the growth equation for per-capita income and population discussed in the preceding section correspond to two working hypotheses defined by a linear and a nonlinear model on a cross-sectional two-period model. Further, we will assume throughout that the relationship between initial conditions and the response variables measuring growth is constant across cities in the sample. ${ }^{3}$ Thus, for per-capita income growth the linear econometric specification is

$$
\Delta y_{i}=\gamma_{0}+\gamma_{1} y_{i o}+\gamma_{2}{ }^{\prime} x_{i o}+\varepsilon_{i},
$$

that extends the above empirical specification by adding an error term 柔 that captures independent and identically distributed (iid) unobserved components that are assumed to exhibit constant variance.

The study of population growth follows similarly. A suitable linear regression equation for measuring population growth is

$$
\Delta l_{i}=\eta_{0}+\eta_{1} l_{i o}+\eta_{2}^{\prime} x_{i o}+\varepsilon_{i}^{*}
$$

$\eta_{0}$ is the intercept and $\eta_{1}$ and $\eta_{2}$ are the parameters that describe the marginal effect of the explanatory variables.

In our framework, the nonlinear alternative, assuming the presence of at most two regimes in per-capita income, is

$$
\Delta y_{i}=\gamma_{0}+\gamma_{11} y_{i o} I\left(y_{i o} \leq u\right)+\gamma_{12} y_{i o} I\left(y_{i o}>u\right)+\gamma_{2}{ }^{\prime} x_{i o}+\varepsilon_{i},
$$

\footnotetext{
${ }^{3}$ As a robustness check, we explore the suitability of alternative threshold models putting the emphasis on nonlinearities on the locational fundamentals rather than in the endogenous income and population variables, see Section 5.4 .
} 
For $\gamma_{11}<\gamma_{12}<0$, the model describes the existence of increasing returns to scale for values of initial per-capita income greater than a threshold value $u$ defined on a compact space $U \in R$, because in that situation the cities with a higher initial per-capita income grow at a higher rate. This can be better observed if (3) is rewritten instead as

$$
y_{i f}=\gamma_{0}+\left(1+\gamma_{11}\right) y_{i o} I\left(y_{i o} \leq u\right)+\left(1+\gamma_{12}\right) y_{i o} I\left(y_{i o}>u\right)+\gamma_{2}{ }^{\prime} x_{i o}+\varepsilon_{i} \text {, }
$$

In equilibrium $\left(E\left[\varepsilon_{i}\right]=0\right)$ this model yields two different balanced growth paths. In the lower regime, per-capita income in equilibrium is equal to $y_{i f}^{(1)}=-\frac{\gamma_{0}+\gamma_{2}{ }^{\prime} x_{i o}}{\gamma_{11}}$ and in the upper regime the per-capita income in equilibrium is $y_{\text {if }}^{(2)}=-\frac{\gamma_{0}+\gamma_{2}{ }^{\prime} x_{i o}}{\gamma_{12}}$. From these expressions and assuming that $\gamma_{0}+\gamma_{2}{ }^{\prime} x_{i o}>0$, it is not difficult to see that $y_{i f}^{(1)}<y_{i f}^{(2)}$ if $\gamma_{11}<\gamma_{12}<0$. The existence of increasing returns leads in equilibrium to two different city sizes for each growth path, however it should be noted that for cities within each growth regime conditional convergence also takes place due to the effect of locational fundamentals. While some NEG models feature a location pattern that can only lead to 'bang-bang' outcomes (a symmetric equilibrium with all the regions completely symmetrical or a corner one with all mobile agents concentrated in one of the regions), our specification allows for the more realistic result of partial agglomeration, fully consistent with others NEG models (see Pflüger and Südekum, 2008).

Our model extends the study of Durlauf and Johnson (1995) by providing a formal procedure for dividing the sample. Thus, this approach is different from those proposed in previous empirical studies of growth convergence clubs, such as the regression tree analysis used by Durlauf and Johnson (1995) and the predictive density of the data used by Canova (2004) to identify different clusters of countries or regions.

A further robustness check to measure the impact of the endogenous and exogenous factors on the growth variables is to consider spatial effects in the different econometric specifications. One fundamental issue missing in most of the empirical studies on crosssectional growth across cities is the spatial dimension. This is noted by Rey and Montouri (1999) and Heckelman (2013); these authors report significant spatial effects in US states for per capita income growth. In a first step, we implement spatial hypothesis tests such as 
the Lagrange multiplier and Moran's I tests (see Moran, 1950; Anselin, 1988) to assess the spillover effects between neighbouring locations in the residuals of the above regression models. In a second step, we estimate a spatial error model and a spatial autoregressive model with the aim of explicitly considering the impact of neighbouring locations on percapita income and population growth. Nevertheless, these analyses must be taken with caution, as Fingleton and López-Bazo (2006) remark in their study. More specifically, these authors show that straightforward applications of spatial econometrics tools are likely to suggest inappropriate empirical growth specifications. Fingleton and López-Bazo (2006) also provide theoretical foundations for appropriate linear specifications incorporating spatial effects with across-region externalities due to knowledge diffusion. Beaumont et al. (2003) estimate a $\epsilon$-convergence model with spatial effects too, allowing for different spatial regimes. They define two different convergence clubs using Exploratory Spatial Data Analysis (a Moran scatterplot) considering a sample of 138 European regions over the period $1980-1995 .^{4}$

In this context, the spatial error model extends model (3) by considering an error variable that satisfies

$$
\varepsilon=\lambda W \varepsilon+v
$$

with $|\lambda|<1$ being a parameter that reflects the effect of the residuals of neighbouring variables on the residual of location $i, W$ a weighting matrix that measures the distances between the different locations and $v_{i}$ an iid random variable that describes the error of the regression model. There exist different possibilities for choosing $W$; we consider a matrix obtained from the coordinates (longitude and latitude) of the locations in order to construct the Euclidean distance between the cities in the empirical analysis. The spatial autoregressive model considers the following econometric specification:

$$
\Delta y_{i}=\gamma_{0}+\rho W \Delta y_{i}+\gamma_{11} y_{i o} I\left(y_{i o} \leq u\right)+\gamma_{12} y_{i o} I\left(y_{i o}>u\right)+\gamma_{2} x_{i o}+\varepsilon_{i},
$$

with $|\rho|<1$ measuring the effect on the response variable of per-capita income growth in neighbouring cities.

\footnotetext{
${ }^{4}$ There are important differences between Beaumont et al. (2003)'s data and our sample. Their sample size is 9 times smaller than ours and they consider regions from different countries, while our sample includes cities
} 
Similarly, the threshold nonlinear specification for population growth that incorporates the spatial error model is

$$
\Delta l_{i}=\eta_{0}+\eta_{11} l_{i o} I\left(l_{i o} \leq v\right)+\eta_{12} l_{i o} I\left(l_{i o}>v\right)+\eta_{2} x_{i o}+\varepsilon_{i},
$$

with $\varepsilon=\lambda W \varepsilon+v$ and $|\lambda|<1$ describing the spatial relationship between the residuals of the nonlinear model. The empirical growth equation considering the spatial autoregressive model is

$$
\Delta l_{i}=\eta_{0}+\rho W \Delta l_{i}+\eta_{11} l_{i o} I\left(l_{i o} \leq v\right)+\eta_{12} l_{i o} I\left(l_{i o}>v\right)+\eta_{2} x_{i o}+\varepsilon_{i},
$$

with $|\rho|<1$ measuring the effect on the response variable of the growth in population in neighbouring locations.

The main difference between previous studies and our method is the procedure for dividing the sample. The threshold parameter $u$ is estimated by the minimization of the

concentrated sum of squared residuals $\hat{S}(u)=e(u)^{\prime} e(u)$ with $e(u)$ being the residual of the corresponding regression model for $u$ fixed (see Hansen, 1997). The estimation of these models is complex and follows different techniques depending on the regression model assumed. Thus, models (1) and (2) can be estimated by ordinary least squares, and standard asymptotic inference results hold. Model (3) is nonlinear and depends on a prior estimation of the threshold value $u$. Once the threshold value has been estimated, OLS methods can be applied to estimate the remainder of the regression model parameters. Inference on the model parameters is achieved via simulation and bootstrap methods that approximate the finite-sample distribution of the supremum of Chi-squared tests. Finally, the estimation of spatial models is also cumbersome and needs to be carried out using maximum likelihood techniques under the assumption that the error variables are normally distributed. Inference follows from applying well-known results for maximum likelihood estimation methods.

\subsection{Testing the three leading theories}

The above models allow us to derive hypothesis tests for each of the leading hypotheses in the analysis of cross-sectional city growth: increasing returns, random growth and socioeconomic and locational fundamentals. For completeness, we also analyse the

from only one country. 
existence of increasing returns to scale in population growth and the explanatory power of the regressors outlined above.

The first hypothesis under study is the existence of increasing returns to scale. Under increasing returns to scale, the accumulation of output beyond a threshold $u$ makes cities more productive ${ }^{5}$; thus, per-capita income growth is endogenous. This hypothesis can be tested using several of the above regression specifications. In particular, for models (3) and (5), the hypothesis of interest can be expressed as $H_{0, I R S}: \gamma_{11}=\gamma_{12}$ vs. $H_{A, I R S}: \gamma_{11} \neq \gamma_{12}$. The differences between both specifications lie on the inclusion or not of spatial effects in the regression equations. The existence of these effects is determined by applying the Lagrange multiplier and Moran's I tests to the residuals of the regression equation (3).

The second hypothesis of interest is to assess the statistical significance of the socioeconomic and locational fundamentals variables. In order to be robust to the existence of increasing returns in per-capita income and spatial effects, we propose testing the hypothesis $H_{0, L}: \gamma_{2}=0$ vs. $H_{A, L}: \gamma_{2} \neq 0$ in model (5). One of the few and pioneering studies concerned with the impact of locational fundamentals is Bloom et al. (2003). These authors are interested in modelling the presence of nonlinearities in percapita income growth from country-level data using a model that incorporates climatological and geographical variables. They propose a Markov regime-switching model in which the probabilities that determine the change of regime depend on these environmental (locational fundamentals) variables.

The last competing theory under analysis is that of random growth, namely, that no explanatory variable helps systematically explain per-capita income growth. The null hypothesis in model (3) is $H_{0, R}: \gamma_{11}=\gamma_{12}=\gamma_{2}=0$. The reader should note that the restriction $\gamma_{11}=\gamma_{12}=0$ is the key assumption of the random growth hypothesis. This is because random growth implies that city growth rates are independent of initial city size. By estimating model (5) instead, this hypothesis can be tested under the implicit presence

\footnotetext{
${ }^{5}$ This is a macroeconomic approach to increasing returns. However, some of our exogenous variables, i.e. human capital variables, are considered in the literature to be a source of agglomeration economics from a microeconomic perspective (see Duranton and Puga, 2004). This micro-treatment of the model is beyond the
} 
of spatial effects from neighbouring locations. A stronger version of the random growth theory assumes that $H_{0, R}: \gamma_{11}=\gamma_{12}=\gamma_{2}=\lambda=0$ or alternatively, for the spatial autoregressive model, that $H_{0, R}: \gamma_{11}=\gamma_{12}=\gamma_{2}=\rho=0$. Under the null hypothesis, percapita income growth is a random variable independently distributed across cities.

Similar tests can be carried out to gauge the empirical relevance of the above models in city population growth. The object of interest is to assess whether population growth in US cities is endogenous or exogenously determined by the set of socioeconomic and locational fundamentals discussed earlier. By accommodating the existence of spatial effects, we robustify the methodology in order to consider the spillover cross-border effects that come from neighbouring locations.

\section{Empirical results}

This section illustrates the above econometric models and tests using data from all US cities with more than 25,000 inhabitants in 2000 (1,173 cities). ${ }^{6}$ The dataset includes urban, climatological, locational and macroeconomic variables on all these 1,173 cities. This sample represents $41.34 \%$ of the total US population in this year, and $52.33 \%$ of the total urban population.

\subsection{Data}

The data came from the censuses for 1990 and 2000 (see Appendix 1 for the details of the data sources). We identified cities as what the US Census Bureau calls “incorporated places". The US Census Bureau uses the generic term incorporated place to refer to a type of governmental unit incorporated under state law as a city, town, borough or village. They are administratively defined "legal" cities; these places have been used recently in the empirical analyses of American city size distribution (Eeckhout, 2004; González-Val, 2010; Ioannides and Skouras, 2013). These cities may occupy a variety of spatial locations in the territory, being either in the core or the periphery or at different distances of more or less

scope of this paper.

${ }^{6}$ There are 141 cities in our sample below the 25.000 inhabitants in 1990 . As the sample is defined according to the largest cities in the latest period, it might imply a slight bias because these are the "winning" cities, namely, those that have presented the highest growth rates (Black and Henderson, 2003). Nevertheless, as the period considered is only one decade, there are almost no "losing cities" excluded that could bias our results. If we consider all the incorporated places with 25,000 or more inhabitants in 1990 according to the US Census Bureau only 10 out of these 1,077 cities fall below the 25,000 inhabitants in 2000. 
large metropolitan areas. In the US, to qualify as a metropolitan area a central city of 50,000 or more inhabitants is needed. Thus, although our cities may occupy very different relative positions in the urban space of metropolitan areas, many of the selected incorporated places that have more than 25,000 inhabitants are the central cities of a metropolitan area.

US urban growth has also been analysed using other geographical units: counties (Beeson et al., 2001), minor civil divisions (Michaels et al., 2012), metropolitan areas (Dobkins and Ioannides, 2001; Black and Henderson, 2003; Ioannides and Overman, 2003) and urbanised areas (Garmestani et al., 2008). However, researchers usually choose between two basic alternatives: administratively defined cities (incorporated places) and metropolitan areas ${ }^{7}$. Both units have advantages. As Glaeser and Shapiro (2003) indicate, metro areas represent urban agglomerations, covering huge areas that are meant to capture labour markets. Metropolitan areas are attractive because they are more natural economic units, while legal cities are political units that usually lie within metropolitan areas, and their boundaries make no economic sense. However, certain factors, such as human capital spillovers, are thought to operate at a very local level (Eeckhout, 2004). The economic area of influence of labour markets and large infrastructure projects such as airports exceeds the boundaries of single legal cities, while the geographical influence of factors such as public services (schools, public transportation, etc.) and local externalities is more reduced. Finally, the population of incorporated places is almost entirely urban, $94.18 \%$ in 2000 , compared with $88.35 \%$ of urban population in metropolitan areas.

One important limitation of incorporated places is the spillover effect or contagion effect between neighbouring localities, which can influence the urban growth process. We use spatial econometrics to deal with this issue. Moreover, the geographic boundaries of census places can change between censuses. As in Glaeser and Shapiro (2003), we address this issue by controlling for change in land area. We acknowledge that this control may not be appropriate because it is also an endogenous variable that may reflect the growth of the city, nevertheless, none of our results change significantly if this control is excluded. Moreover, we also eliminate incorporated places that either more than doubled land area

\footnotetext{
${ }^{7}$ In fact, information on most of the variables used in this study is only available at the place or metropolitan area level.
} 
(37 cities) or lost more than $10 \%$ of their land area (five cities). This correction eliminates 42 extreme cases where the city in 1990 is something very different from the city in 2000. The explicative variables chosen are similar to those reported in other studies on city growth in the US and city size, and correspond to the initial 1990 values. The influence of some of these variables on determining city size has been empirically illustrated in other studies such as Glaeser et al. (1995) or Glaeser and Shapiro (2003). Our aim is to introduce variables to control for some of the already known empirical determinants of city growth (human capital, density, weather). Table 1 presents the variables, which can be grouped into four types: urban sprawl variables, human capital variables, productive structure variables and weather variables.

Urban sprawl variables aim to reflect the effect of city size on urban growth. For this, we use population density, growth in land area from 1990 to 2000 (as a control for boundary changes) and the variable median travel time to work, which represents the commuting cost borne by workers. Commuting time is endogenous and depends in part on the spatial organisation of cities and location choice within cities. The median commuting time may reflect traffic congestion in larger urbanised areas as well as the size of the city in less densely populated areas, or the remoteness of location for rural towns; in other words, the idea that as a city's population increases, so do the costs in terms of individuals' travel time to work.

Regarding human capital variables, many studies demonstrate the influence of human capital on city size, as cities with better educated inhabitants tend to grow more. For example, Glaeser and Saiz (2003) analyse the period 1970-2000 and show that skilled cities are more productive economically. We take two human capital variables: population with a high school graduate or higher degree and population with some college or higher degree. The former represents a wider concept of human capital, while the latter centres on higher educational levels (some college, Associate degree, Bachelor's degree and Graduate or professional degree).

The third group of variables, referring to productive structure, contains the unemployment rate and distribution of employment by sector. The distribution of labour among the various productive activities provides valuable information about other city characteristics. Thus, the employment level in the primary sector (agriculture, forestry, 
fishing and hunting and mining) also represents a proxy for the natural physical resources available to the city (cultivable land, port, etc.) Like construction, this sector is also characterised by constant or even decreasing returns to scale. Employment in manufacturing informs us about the level of local economies of scale in production, as this sector normally presents increasing returns to scale. A proxy for the market size of the city is the employment in commerce, whether retail or wholesale. Information is also included on employment in the most relevant activities in the services sector: finance, insurance and real estate; educational, health, and other professional and related services; and employment in public administration.

We disaggregate geography into physical geography and the socioeconomic environment and control for both types of characteristics. We use a temperature index as a measure of weather. The temperature discomfort index (TEMP_INDEX) represents each city's climate amenity, and is constructed in a similar way as in Zheng et al. (2010). It is defined as:

$T E M P_{-} I N D E X_{k}=\sqrt{\begin{array}{l}\left(\text { Winter_temperature }_{k}-\min (\text { Winter_temperature })\right)^{2}+ \\ +\left(\text { Summer_temperature }_{k}-\max (\text { Summer_temperature })\right)^{2}\end{array}}$

where Winter_temperature and Summer_temperature are the 30-year average values in January and July in Fahrenheit degrees computed from the data recorded during the period 1971-2000. The index represents the distance of the $k$ ecity's winter and summer temperatures from the mildest winter and summer temperatures across the 1,173 cities. A higher TEMP_INDEX means a harsher winter or a hotter summer, which makes the city a harder place in which to live or produce. Annual precipitation in inches and the percentage of water area over the total land area are also included.

We introduce several dummies to provide information about geographic localisation; these take a value of one depending on the region (Northeast, Midwest, South or West) in which the city is located ${ }^{8}$. These dummies show the influence of a series of variables for which individual data are not available for all places, and which could be directly related to the geographical situation (access to the sea, presence of natural

\footnotetext{
${ }^{8} \mathrm{We}$ also introduced state-level dummies into some of the preliminary estimations, but they were not significant.
} 
resources, etc.) or, especially, the socioeconomic environment (differences in economic and productive structures).

\subsection{Econometric analysis of per-capita income growth}

We first carry out an exploratory analysis of the explanatory variables comprising the set of locational fundamentals. Thus, Table 1 reports the average values of the explanatory variables over the whole sample of US cities and over the subgroup of cities in the low regime group. These values reflect important differences in the productive structure, education levels and location between these groups. Employment in agriculture and the exploitation of natural resources is higher than average in the cities in the low income group. Public administration also makes a greater than average contribution in these cities. Interestingly, we find that most of these cities are located in the South and West regions of the US, indicating an important locational or regional effect on per-capita income growth. Educational levels, measured by the population with a high school degree or college education, are also well below the average. The descriptive analysis of the sectors of productive activity also shows that the financial, insurance and real estate sectors are associated with high per-capita income levels. Unemployment rates between both groups of cities are also in stark contrast; unemployment is clearly higher in the cities in the low regime group.

Second, we consider the extent of spatial dependence in the data and assess whether this dependence is robust to the inclusion of the locational (geographical) fundamentals defined in this study. To do this we apply the Lagrange multiplier and Moran's I tests to the residuals of the nonlinear regression analysis (3). Table 2 reports the p-values of these tests. These p-values provide clear evidence of the statistical significance of the spatial effects for the spatial error model, whereas for the spatial autoregressive model the statistical evidence is mixed.

Third, we statistically assess for the presence of threshold nonlinearities in the above spatial models. To do this, the threshold $u$ is estimated using the Hansen (1997) procedure that minimises the concentrated sum of squares of the residual series indexed by $u$, with $u$ defined inside a compact set in the real line. We obtain a threshold estimate for the initial per-capita income of $\hat{u}_{n}=9.2289$, which corresponds to $\$ 10,187$. This threshold 
estimate defines a lower regime characterised by the parameter $\gamma_{11}=-0.1522$ for the spatial error model and $\gamma_{11}=-0.1513$ for the spatial autoregressive model. Meanwhile, the upper regime is defined by $\gamma_{12}=-0.1464$ for the spatial error model and $\gamma_{12}=-0.1459$ for the spatial autoregressive model (see columns 3 and 6 in Table 3). These results indicate the existence of two distinct equilibria in per-capita income growth. There are 104 cities in the lower regime. The p-value of the nonlinearity test for the spatial versions of model (3) given by (4) and (5) is zero, demonstrating that the differences between $\gamma_{11}$ and $\gamma_{12}$ are statistically significant in both modelling strategies. Interestingly, whereas the estimates of the regression model parameters are similar across the spatial nonlinear models, the spatial effects are in sharp contrast. Thus, the spatial error model reports evidence of negative serial correlation between the residuals of model (3) and provides further support to the choice of model (4) for fitting the spatial dependence in the model errors. In contrast, the parameter estimates of the spatial autoregressive model (5) indicate that the effect of percapita income between neighbouring locations vanishes when controls for geography and social and economic factors are included.

These results are consistent with economic growth theory in that the sign of the parameters is negative, indicating convergence towards equilibrium. Barro and Sala-iMartin (1992), Evans and Karras (1996), Sala-i-Martin (1996) and Evans (1997) also find statistically significant $\beta$-convergence effects using US state-level data, while Higgins et al. (2006) use US county-level data to document statistically significant $\beta$-convergence effects across the US. Our analysis is more informative since it provides empirical evidence of the existence of a threshold value beyond which cities achieve higher growth rates, as $\gamma_{11}<\gamma_{12}<0$.

The second question that this article aims to answer is whether socioeconomic and locational fundamentals can add explanatory power to the nonlinear growth model discussed above. To assess this, we estimate both spatial models for the regression specification without the covariates $x_{o}$ and without the subset of socioeconomic covariates, namely productive structure and human capital variables (see Table 3). The results are conclusive in showing the statistical relevance of including both sets of regressors. The difference in log-likelihood between the models in Table 3 and the corresponding 
likelihood ratio test confirm this finding. Furthermore, the signs of the coefficients are consistent with related studies (Glaeser et al., 1995). The table also shows the statistical significance of the spatial autoregressive model if no other covariate beyond lagged percapita income is included in the regression specification. This finding implies that percapita income in neighbouring locations helps explain per-capita income. Interestingly, the statistical relevance of this model vanishes if the set of regressors that contain the locational fundamentals are included in the multiple regression model. Further, the analysis of the differences in log-likelihood between models also confirms the statistical significance of the socioeconomic variables. These results provide mounting evidence against a strong version of the random growth theory.

\subsection{Econometric analysis of population growth}

The analysis of city growth characteristics also concerns the study of population. The supremum nonlinearity test in Hansen (1997) reports a p-value of zero and a threshold estimate of $\hat{u}_{n}=9.9657$, which leaves 60 observations below the threshold and corresponds to a value of 21,093 inhabitants. Recently, there has also been rising interest in different regimes and switching points in the city size distribution literature. Ioannides and Skouras (2013) estimate a switching point between the body of the city size distribution and its upper tail. Using 2000 Census Places data, they show that there is a switching point from a lognormal to a Pareto law. Curiously, the threshold level we find with our nonlinear growth model is similar to one of the switching points estimated by Ioannides and Skouras (2013). Their estimate for the CDGPR mixture model inspired by Combes et al. (2012) is 16,312 inhabitants with a standard deviation of 5,401.

The next step is to decide on the appropriate regression specification to test for the existence of increasing returns to scale and to assess the importance of socioeconomic and locational fundamentals for explaining growth in city population. Table 2 provides mixed evidence on the relevance of using spatial models to describe the relationship between population growth and the sets of regressors in the study. Whereas the Lagrange multiplier test rejects the null hypothesis of no spatial effects, Moran’s I test finds no statistical evidence to reject the null hypothesis. Based on these results, we estimate models (6) and (7), which are robust to spatial effects. 
Table 4 collects the estimates of the model parameters of the regression models (6) and (7). The parameter estimates in the low growth regime are $\eta_{11}=-0.0765$ for the spatial error model and $\eta_{11}=-0.0711$ for the spatial autoregressive model. For the high growth regime, we have $\eta_{12}=-0.0691$ for the spatial error model and $\eta_{12}=-0.0635$ for the spatial autoregressive model (columns 3 and 6 in Table 4). These values suggest the existence of increasing returns on population growth in US cities, because $\eta_{11}<\eta_{12}<0$ (see models (6) and (7)). The p-value of the corresponding nonlinearity test is zero giving further support to the multiple equilibria hypothesis. Table 4 details the specific marginal effects of the different variables. Our results show that the unemployment rate has no significant effect on income growth but a very small but positive and statistically significant influence on population growth. Unemployment's main effect concerns individuals' movements rather than city’s productivity.

In contrast to the analysis of income growth, both spatial regression models are statistically significant in all specifications for the study of population growth. Interestingly, whereas the spatial error model reports a negative spatial correlation between the residuals, the spatial autoregressive model indicates a positive relationship between the population growth rates in neighbouring locations. This phenomenon suggests that population city growth can occur because of population inflows at a regional level.

Table 1 also shows interesting insights into the differences between those cities with low population growth rates and the national average. In contrast to the per-capita income analysis, unemployment rates are well below the average for these cities despite slightly lower than average educational levels. Interestingly, the structure of productive activity is highly diversified with important contributions by the construction, manufacturing and agriculture sectors. Location is also important; there are no cities in our sample with these characteristics in the Northeast region of the US.

A comparison between the models in Tables 3 and 4 shows similar values for the parameter estimates of the regressors. One exception is the parameter values of the two human capital variables under study; increases in the percentage of population with the highest education level (some college or higher degree) have a positive impact on population growth, while the wider concept of human capital (high school graduate or 
higher degree) has a significant negative effect. These results coincide with those of other studies that analyse the influence of education on city growth. Glaeser and Shapiro (2003) also find that workers have a different impact depending on their education levels (high school or college). Finally, the study of environmental variables shows that the influence of climate on population growth is weak, while the temperature index has a negative effect on growth, as expected: a higher index means that the city is a harder place in which to live. However, this coefficient loses significance in some specifications. The same applies to the precipitation variable.

\subsection{Robustness analysis}

To assess the robustness of the results discussed in the preceding subsection, we carry out a further empirical analysis. The aim of the following study is to assess the importance of the threshold model in both of the above growth equations for determining the presence of nonlinearities in the above convergence models. To do this we conduct three alternative regression studies that capture potential nonlinear effects of lagged per-capita income and population in the respective growth variables. First, we replace the threshold variables by a polynomial of order three. This alternative modelling strategy explores the statistical significance of higher order effects without requiring complex regression analysis. Further, this approach is highly tractable as it relies on standard multiple linear regression analysis. Note, however, that the method is not as explicit as the threshold model in determining the region exhibiting the nonlinearities. Second, we consider a model the makes allowance for interactions between the locational fundamentals and the lagged of per-capita income and population. By doing so, the model aims to capture multiplicative effects of the variable of interest on the response variable that are determined by the interaction of the variable with the rest of regressors. In some cases, it seems hard to separate locational fundamentals from increasing returns (i. e., the presence of a natural harbor or natural resources might be the cause of local increasing returns; Ellison and Glaeser, 1999); this new specification allows some variation of the fundamental parameters with city size. Third, we investigate the suitability of considering threshold nonlinearities on other variables instead of on per-capita income and lagged population.

Table 5 reports the results of the spatial tests to determine the existence of spatial effects in the regression model considering the polynomial of order three, instead of the 
threshold variables, and the regressors considering locational fundamentals. The table shows clear evidence of such effects both for the spatial error model and the spatial lag model. Table 6 confirms this evidence and supports the nonlinearity of the lagged percapita income in explaining per-capita income growth. Note the lower log-likelihood values of the models in Table 6 compared to their counterparts in Table 4. These statistics suggest the better fit of the threshold model than of the polynomial and confirm the superior performance of threshold models for capturing piecewise nonlinearities in the data. The results for the polynomial model fitted to population growth are not reported because in this example the algorithm to estimate the model parameters only shows convergence for the simple model without locational fundamentals ${ }^{9}$. Surprisingly, the polynomial terms are not statistically significant in the simple case. The statistics of the spatial tests reported in Table 7 provide further empirical evidence on the presence of such effects under other nonlinear specifications of the baseline model. Table 8 reports the results for the spatial regression models that incorporate interactions between the lagged income variable and the rest of explanatory variables. The results suggest some relevance of the interactions between variables, the log-likelihood function is high and comparable in some cases to the threshold model. Interestingly, some of the locational fundamentals lose statistical significance when combined with the rest of regressors incorporating the interactions. The results corresponding to the analysis of population growth are surprisingly disappointing. None of the locational fundamentals is significant in the model. The third robustness analysis explores the suitability of alternative threshold models putting the emphasis on nonlinearities on the locational fundamentals rather than in the endogenous income and population variables. Unreported results provide mixed evidence on the success of such models in explaining income and population growth. Thus, we find that human capital variables and some productive structure variables such as manufactures, wholesale and retail trade, and professional services exhibit nonlinearities in explaining city growth. Nevertheless, these nonlinearities in the locational fundamentals do not change the hypotheses tested nor the main results.

Overall, the robustness analysis confirms the existence of nonlinearities in the relationship between lagged income and lagged population and next period's growth. The

\footnotetext{
${ }^{9}$ These results are available from the authors upon request.
} 
threshold model shows a very strong performance in terms of model fit compared to the polynomial model and the model considering interactions with the locational fundamentals.

\section{Conclusion}

The empirical analysis of city growth has long been open to debate by researchers in urban and geographical economics. This article has discussed three competing theories given by increasing returns to scale leading to multiple equilibria, the importance of locational fundamentals in determining the different equilibrium paths and leading to conditional convergence outcomes or the absence of any of these theories. To assess which of these theories is better supported by the data on city growth we have developed a cross-sectional threshold model that makes allowance in the absence of shocks for two distinct equilibrium paths. This model incorporates a set of socio-economic and climatological variables that proxy the locational fundamentals. We have also considered the impact of spatial effects in city growth due to neighbouring locations and not reflected by our set of regressors.

The conclusions of our empirical analysis that cover a sample comprising the 1,173 largest US cities confirm the existence of increasing returns to scale on both city per-capita income and population growth in the 1990s. The threshold values that determine these nonlinearities correspond to wealth and population levels near the left end of their respective distributions, supporting the view that there exist some barriers to growth in small locations. This finding is consistent with the literature on poverty traps in macroeconomic studies of cross-sectional economic growth at the country level. Nevertheless, our results also highlight the importance of the locational fundamentals in explaining differences in growth across cities. These variables have in fact more explanatory power than the threshold variables chosen to capture the endogenous growth process. Both sets of results combined suggest that the process of city growth is determined to a large extent by initial conditions. Nevertheless, there are also some other factors that contribute to growth such as climate, the level of education or the composition of the productive structure, amongst others.

Our results also suggest other sources of city growth not captured by the above theories and the corresponding empirical models. Thus, we observe strong spatial effects 
pointing out the significance of neighbouring effects in determining city growth. These effects can be due to some common characteristic shared by cities in a specific region such as climate, legislation or economic policies that make cities more or less appealing for attracting population and wealth. The importance of these spatial effects suggest that there may be other theories, beyond and above the three aforementioned, building on the existence of clustering effects at the county or region level that can provide alternative explanations of city growth. Thus, these spatial effects can capture internal economies of scale, large industry effects spilling over a region, cultural effects characteristic of a region or state or knowledge diffusion across locations. The understanding of the variables behind the spatial effects is beyond the scope of this paper and is left for future research.

Finally, it is worth mentioning that the period considered does not provide conclusive evidence of one theory against the others. This is because the growth process observed in this decade can change in former or later periods depending on several factors (e.g. innovation cycles; see Robson, 1973; Favaro and Pumain, 2011). 


\section{References}

Anselin, L. (1988). Lagrange multiplier test diagnostics for spatial dependence and spatial heterogeneity. Geographical Analysis, 20: 1-17.

Baumol, W. (1986). Productivity Growth, Convergence, and Welfare: What the Long-Run Data Show. American Economic Review, 76: 1072-1085.

Barro, R. J., and X. Sala-i-Martin (1992). Convergence. Journal of Political Economy, 100(2): 223-251.

Barro, R. J., and X. Sala-i-Martin (2004). Economic Growth. MIT Press: Cambridge, MA.

Beaumont, C., C. Ertur and J. Le Gallo (2003). Spatial convergence clubs and the European regional growth process, 1980-1995. In B. Fingleton (ed) European Regional Growth: Springer-Verlag, 131-158.

Beeson, P.E., D. N. DeJong, and W. Troesken (2001). Population Growth in US Counties, 1840-1990. Regional Science and Urban Economics, 31: 669-699.

Berry, B. J. L. and J. D. Kasarda (1977) Contemporary Urban Ecology, New York: Macmillan Publishing Co.

Black, D., and V. Henderson (1999). A Theory of Urban Growth. Journal of Political Economy, 107(2): 252-284.

Black, D., and V. Henderson (2003). Urban evolution in the USA. Journal of Economic Geography, 3(4): 343-372.

Bloom, D., D. Canning, and J. Sevilla (2003). Geography and Poverty traps. Journal of Economic Growth, 8: 355-378.

Bosker, E. M., S. Brakman, H. Garretsen, and M. Schramm (2007). Looking for multiple equilibria when geography matters: German city growth and the WWII shock. Journal of Urban Economics, 61: 152-169.

Bosker, E. M., S. Brakman, H. Garretsen and M. Schramm (2008). A century of shocks: the evolution of the german city size distribution 1925 - 1999. Regional Science and Urban Economics 38: 330-347.

Canova, F. (2004). Testing for convergence clubs in income per capita: a predictive density 
approach. International Economic Review, 45: 49-77.

Champernowne, D. (1953). A model of income distribution. Economic Journal, LXIII: 318-351.

Chasco, C, A. López, and R. Guillain (2012). The influence of geography on the spatial agglomeration of production in the European Union. Spatial Economic Analysis, 7(2): 247263.

Combes, P.-P., G. Duranton, L. Gobillon, D. Puga, and S. Roux (2012). The Productivity Advantages of Large Cities: Distinguishing Agglomeration from Firm Selection. Econometrica, 80(6): 2543-2594.

Combes, P.-P., G. Duranton, and H. G. Overman (2005). Agglomeration and the adjustment of the spatial economy. Papers in Regional Science, 84(3): 301-530.

Davis, D. R., and D. E. Weinstein (2002). Bones, Bombs, and Break Points: The Geography of Economic Activity. The American Economic Review, 92(5): 1269-1289.

Davis, D. R., and D. E. Weinstein (2008). A search for multiple equilibria in urban industrial structure. Journal of Regional Science, 48(1): 29-65.

De Long, J. B. (1988). Productivity Growth, Convergence, and Welfare: Comment. American Economic Review, 78: 1138-1154.

Diamond, P. A. (1965). National Debt in a Neoclassical Growth Model. American Economic Review, 55: 1126-1150.

Dobkins, L. H., and Y. M. Ioannides (2001). Spatial interactions among US cities: 19001990. Regional Science and Urban Economics, 31: 701-731.

Duranton, G., and D. Puga (2001). Nursery Cities: Urban Diversity, Process Innovation, and the Life Cycle of Products. American Economic Review 91(5), 1454-1477.

Duranton, G., and D. Puga (2004). Micro-Foundations of Urban Agglomeration Economies. Handbook of Urban and Regional Economics, Vol. 4, J. V. Henderson and J. F. Thisse, eds. Amsterdam: Elsevier Science, North-Holland, Chapter 48, pp. 2064-2117.

Durlauf, S., and P. Johnson (1995). Multiple Regimes and Cross-country Growth Behavior. Journal of Applied Econometrics, 10: 365-384. 
Eaton, J., and Z. Eckstein, (1997). Cities and Growth: Theory and Evidence from France and Japan. Regional Science and Urban Economics, 27(4-5): 443-474.

Eeckhout, J. (2004). Gibrat's Law for (All) Cities. American Economic Review, 94(5): $1429-1451$.

Ellison, G., and E. L. Glaeser (1999). The geographic concentration of industry: Does natural advantage explain agglomeration? American Economic, Review Papers and Proceedings, 89(2): 311-316.

Evans, P. (1997). How Fast Do Economies Converge? Review of Economics and Statistics, 79(2): 219-225.

Evans, P., and G. Karras (1996). Do Economies Converge? Evidence from a Panel of U.S. States. Review of Economics and Statistics, 78(3): 384-388.

Favaro, J.-M., and D. Pumain (2011). Gibrat Revisited: An Urban Growth Model Incorporating Spatial Interaction and Innovation Cycles. Geographical Analysis, 43: 261286.

Fernihough, A., and K. Hjortshøj O’Rourke, (2014). Coal and the European industrial revolution. NBER Working Paper No. 19802.

Fingleton, B., and E. López-Bazo (2006). Empirical growth models with spatial effects. Papers in Regional Science, 85(2): 177-198.

Fujita, M. (1976). Spatial patterns of urban growth: Optimum and market. Journal of Urban Economics, 3(3): 209-241.

Gabaix, X. (1999). Zipf's law for cities: An explanation. Quarterly Journal of Economics, 114(3): 739-767.

Garmestani, A. S., C. R. Allen, and C. M. Gallagher (2008). Power laws, discontinuities and regional city size distributions. Journal of Economic Behavior \& Organization, 68: 209-216.

Glaeser, E.L. (2000). The New Economics of Urban and Regional Growth. In Chapter 5 of The Oxford Handbook of Economic Geography. Edited by G.L. Clark, M.P. Feldman and M.S. Gertler. Oxford University Press. 
Glaeser, E. L., and A. Saiz (2003). The Rise of the Skilled City. Harvard Institute of Economic Research, Discussion Paper number 2025.

Glaeser, E. L., J. A. Scheinkman, and A. Shleifer (1995). Economic growth in a crosssection of cities. Journal of Monetary Economics, 36: 117-143.

Glaeser, E. L. and J. Shapiro (2003). Urban Growth in the 1990s: Is city living back? Journal of Regional Science, 43(1): 139-165.

González-Val, R. (2010). The Evolution of the US City Size Distribution from a Long-run Perspective (1900-2000). Journal of Regional Science, 50(5): 952-972.

González-Val, R. (2014). Cross-sectional Growth in US Cities from 1990 to 2000. Journal of Geographical Systems, forthcoming. DOI: 10.1007/s10109-014-0204-0

Hansen, B. E. (1997). Inference in TAR models. Studies in Nonlinear Dynamics and Econometrics, 2: 1-14.

Heckelman, J. C. (2013). Income convergence among U.S. states: cross-sectional and time series evidence. Canadian Journal of Economics/Revue canadienne d'économique, 46(3): 1085-1109.

Henderson, J. V. (1974). The Sizes and Types of Cities. The American Economic Review, Vol. 64(4): 640-656.

Higgins, M. J., D. Levy, and A. T. Young (2006). Growth and Convergence Across the U.S.: Evidence from County-Level Data. Review of Economics and Statistics, 88(4): 671681.

Ioannides, Y. M., and H. G. Overman (2003). Zipf's law for cities: An empirical examination. Regional Science and Urban Economics, 33: 127-137.

Ioannides, Y. M., and S. Skouras (2013). US city size distribution: Robustly Pareto, but only in the tail. Journal of Urban Economics, 73: 18-29.

Le Gallo, J., C. Ertur and C. Baumont (2003). A spatial econometric analysis of convergence across European regions, 1980-1995. In B. Fingleton (ed) European Regional Growth: Springer-Verlag, 99-129.

López-Bazo, E., E. Vayá, and M. Artís (2004). Regional externalities and growth: evidence from European regions. Journal of Regional Science, 44: 43-73. 
Mankiw, N. G., D. Romer, and D. N. Weil (1992). A Contribution to the Empirics of Economic Growth. The Quarterly Journal of Economics, 107(2): 407-437.

Melo, P. C., D. J. Graham, and R. B. Noland (2009). A Meta-analysis of Estimates of Urban Agglomeration Economies. Regional Science and Urban Economics, 39: 332-342.

Michaels, G., F. Rauch, and S. J. Redding (2012). Urbanization and Structural Transformation. The Quarterly Journal of Economics, 127(2): 535-586.

Moran, P. A. P. (1950). Notes on Continuous Stochastic Phenomena. Biometrika, 37(1): $17-23$.

Palivos, T., and P. Wang (1996). Spatial agglomeration and endogenous growth. Regional Science and Urban Economics 26, 645-669.

Pflüger, M., and J. Südekum (2008). A synthesis of footloose-entrepreneur new economic geography models: when is agglomeration smooth and easily reversible? Journal of Economic Geography, Vol. 8(1): 39-54.

Plummer, P., and E. Sheppard (2006). Geography Matters: Agency, Structures and Dynamics at the Intersection of Economics and Geography. Journal of Economic Geography, 6(5): 619-637.

Quah, D. (1997). Empirics for Growth and Distribution: Stratification, Polarization, and Convergence Clubs. Journal of Economic Growth, 2: 27-59.

Rappaport, J. (2007). Moving to nice weather. Regional Science and Urban Economics, 37(3): 375-398.

Rey, S. J., and B. D. Montouri (1999). US regional income convergence: A spatial econometric perspective. Regional Studies, 33(2): 143-156.

Roback, J. (1982). Wages, Rents, and the Quality of Life. Journal of Political Economy, 90(6): 1257-1278.

Robson, B. T. (1973). Urban growth: an approach. London: UK, Methuen.

Roos, M. W. M. (2005). How important is geography for agglomeration? Journal of Economic Geography, Vol. 5(5): 605-620.

Rosenthal, S. S., and W. C. Strange (2004). Evidence on the Nature and Sources of 
Agglomeration Economies. Handbook of Urban and Regional Economics, Vol. 4, J. V. Henderson and J. F. Thisse, eds. Amsterdam: Elsevier Science, North-Holland, Chapter 49, pp. 2119-2171.

Sala-i-Martin, X. (1996). Regional Cohesion: Evidence and Theories of Regional Growth and Convergence. European Economic Review, 40: 1325-1352.

Simon, H. (1955). On a class of skew distribution functions. Biometrika, 42: 425-440.

Solow, R. M. (1956). A Contribution to the Theory of Economic Growth. The Quarterly Journal of Economics, 70(1): 65-94.

Zheng, S., M. E. Kahn, and H. Liu (2010). Towards a system of open cities in China: Home prices, FDI flows and air quality in 35 major cities. Regional Science and Urban Economics, 40: 1-10. 


\section{Appendix: Data sources and Tables}

The US Census Bureau offers information on a large number of variables for different geographical levels, available on its website: www.census.gov. Using the American FactFinder tool, you can download data from decennial census in 1990 and 2000 on most of the variables in our study: population and per-capita income levels in 1990 and 2000, median travel time to work, educational variables and productive structure variables. Data on active population and unemployed people, required to construct the unemployment rates, can also be found there. The data set containing all these economic and demographic city variables used in the regressions is the 1990 Census Summary Tape File 3 (STF 3).

Land and water area data, needed to construct the variables land area growth, population per square mile and percentage of water area, also come from the US Census Bureau:

http://www.census.gov/population/www/censusdata/places.html, and http://www.census.gov/geo/www/gazetteer/places2k.html.

Finally, the source for the weather variables (temperatures used to construct the discomfort index and annual precipitation) is the US National Oceanic and Atmospheric Administration (NOAA), National Climatic Data Center (NCDC), Climatography of the United States, Number 81, available online at:

http://cdo.ncdc.noaa.gov/cgi-bin/climatenormals/climatenormals.pl. 
Table 1. Summary table: means and standard deviations, city variables in 1990

\begin{tabular}{|c|c|c|c|c|c|c|}
\hline \multirow[b]{2}{*}{ Variable } & \multicolumn{2}{|c|}{ All sample } & \multicolumn{2}{|c|}{ Bottom income group } & \multicolumn{2}{|c|}{ Bottom population group } \\
\hline & Mean & Stand. dev. & Mean & Stand. dev. & Mean & Stand. dev. \\
\hline Population Growth (ln scale), 1990-2000 & 0.14 & 0.20 & 0.15 & 0.28 & 0.62 & 0.30 \\
\hline Per-Capita Income Growth (ln scale), 1989-1999 & 0.38 & 0.10 & 0.42 & 0.13 & 0.48 & 0.14 \\
\hline \multicolumn{7}{|l|}{ Urban sprawl } \\
\hline Land Area Growth (ln scale) & 0.09 & 0.14 & 0.14 & 0.19 & 0.22 & 0.20 \\
\hline Population per Square Mile & 7.90 & 0.77 & 8.03 & 0.91 & 7.05 & 0.73 \\
\hline Median Travel Time to Work (in minutes) & 20.68 & 4.95 & 19.49 & 4.73 & 22.82 & 4.84 \\
\hline \multicolumn{7}{|l|}{ Human capital variables } \\
\hline Percent population 18 years and over: Some college or higher degree & 37.85 & 11.76 & 27.09 & 15.08 & 37.02 & 10.41 \\
\hline Percent population 18 years and over: High school graduate or higher degree & 58.55 & 9.67 & 45.78 & 14.52 & 56.35 & 9.52 \\
\hline \multicolumn{7}{|l|}{ Productive structure variables } \\
\hline Unemployment rate & 6.24 & 2.83 & 10.83 & 4.22 & 4.90 & 3.00 \\
\hline \multicolumn{7}{|l|}{ Percent employed civilian population 16 years and over: } \\
\hline Agriculture, forestry, fishing, and mining & 1.95 & 2.62 & 3.93 & 5.53 & 3.51 & 4.24 \\
\hline Construction & 5.62 & 2.00 & 5.54 & 2.35 & 6.51 & 2.52 \\
\hline Manufacturing (durable and nondurable goods) & 17.46 & 7.54 & 17.59 & 9.15 & 18.81 & 6.26 \\
\hline Wholesale and Retail trade & 22.51 & 3.01 & 22.67 & 3.37 & 22.22 & 3.37 \\
\hline Finance, insurance, and real estate & 7.08 & 2.62 & 4.56 & 1.39 & 7.08 & 2.53 \\
\hline Educational, health, and other professional and related services & 24.19 & 6.75 & 24.33 & 9.11 & 20.47 & 4.09 \\
\hline Public administration & 4.70 & 3.36 & 5.33 & 3.98 & 4.75 & 2.71 \\
\hline \multicolumn{7}{|l|}{ Weather } \\
\hline Temperature index & 65.59 & 11.40 & 68.88 & 10.78 & 64.37 & 9.50 \\
\hline Annual precipitation (inches) & 34.90 & 14.56 & 30.84 & 17.27 & 33.94 & 15.07 \\
\hline Percentage of water area & 0.09 & 0.33 & 0.05 & 0.12 & 0.02 & 0.04 \\
\hline \multicolumn{7}{|l|}{ Regional dummy variables } \\
\hline Northeast Region & $13.30 \%$ & & $8.65 \%$ & & $0.00 \%$ & \\
\hline Midwest Region & $28.64 \%$ & & $17.31 \%$ & & $30.00 \%$ & \\
\hline South Region & $27.54 \%$ & & $35.58 \%$ & & $35.00 \%$ & \\
\hline West Region & $30.52 \%$ & & $38.46 \%$ & & $35.00 \%$ & \\
\hline
\end{tabular}

Note: Average values of the variables under study across 1,173 observations (All sample), across the bottom per-capita income group

(104 observations) and across bottom population group (60 observations). Source: 1990 and 2000 Census, www.census.gov. 
Table 2. Diagnostics for per-capita income and population models

\begin{tabular}{lcccc}
\hline & \multicolumn{2}{c}{ Income growth model } & \multicolumn{2}{c}{ Population growth model } \\
\hline Test & Statistic & p-value & Statistic & p-value \\
\hline Spatial error: & & & & \\
$\quad$ Moran's I & 1.253 & 0.210 & 1.124 & 0.261 \\
$\quad$ Lagrange multiplier & 1039.676 & 0.000 & 252.767 & 0.000 \\
$\quad$ Robust Lagrange multiplier & 1080.431 & 0.000 & 268.014 & 0.000 \\
\hline Spatial lag: & & & & \\
$\quad$ Lagrange multiplier & 1.999 & 0.157 & 8.516 & 0.004 \\
$\quad$ Robust Lagrange multiplier & 42.754 & 0.000 & 23.762 & 0.000 \\
\hline
\end{tabular}

Note: The null hypothesis in all tests is that there is zero spatial autocorrelation. 
Table 3. Per-capita income growth models

\begin{tabular}{|c|c|c|c|c|c|c|}
\hline \multirow[b]{2}{*}{$\begin{array}{l}\text { Variables } \\
\end{array}$} & \multicolumn{3}{|c|}{ Spatial error models } & \multicolumn{3}{|c|}{ Spatial lag models } \\
\hline & $(1)$ & $(2)$ & (3) & (4) & (5) & (6) \\
\hline Per-Capita Income (ln scale) in $1989 \leq u$ & $\begin{array}{c}-0.0683 * * * \\
(0.0097)\end{array}$ & $\begin{array}{c}-0.0521 * * * \\
(0.0115)\end{array}$ & $\begin{array}{c}-0.1522 * * * \\
(0.0187)\end{array}$ & $\begin{array}{c}-0.0361 * * * \\
(0.1385)\end{array}$ & $\begin{array}{c}-0.0457 * * * \\
(0.0126)\end{array}$ & $\begin{array}{c}-0.1513^{* * * *} \\
(0.0198)\end{array}$ \\
\hline Per-Capita Income (ln scale) in $1989>u$ & $\begin{array}{c}-0.0603^{* * *} \\
(0.0092) \\
\end{array}$ & $\begin{array}{c}-0.0457^{* * *} \\
(0.0109) \\
\end{array}$ & $\begin{array}{c}-0.1464^{* * *} \\
(0.0183) \\
\end{array}$ & $\begin{array}{c}-0.0308^{* *} \\
(0.1311) \\
\end{array}$ & $\begin{array}{c}-0.0402^{* * * *} \\
(0.0119) \\
\end{array}$ & $\begin{array}{c}-0.1459 * * * \\
(0.0193) \\
\end{array}$ \\
\hline \multicolumn{7}{|l|}{ Urban sprawl } \\
\hline Land Area Growth (In scale) & & $\begin{array}{c}0.0738^{* * *} \\
(0.0193)\end{array}$ & $\begin{array}{c}0.0752 * * * \\
(0.0187)\end{array}$ & & $\begin{array}{c}0.0934^{* * * *} \\
(0.0195)\end{array}$ & $\begin{array}{c}0.0964 * * * \\
(0.0191)\end{array}$ \\
\hline Population per Square Mile (ln scale) & & $\begin{array}{c}-0.0193^{* * *} \\
(0.0039)\end{array}$ & $\begin{array}{c}-0.0239 * * * \\
(0.0042)\end{array}$ & & $\begin{array}{c}-0.0261^{* * *} \\
(0.0042)\end{array}$ & $\begin{array}{c}-0.0324 * * * \\
(0.0043)\end{array}$ \\
\hline Median Travel Time to Work (in minutes) & & $\begin{array}{c}0.0017 * * \\
(0.0006) \\
\end{array}$ & $\begin{array}{c}0.0031^{* * * *} \\
(0.0007)\end{array}$ & & $\begin{array}{c}0.0002 \\
(0.0007) \\
\end{array}$ & $\begin{array}{l}0.00012 \\
(0.0008) \\
\end{array}$ \\
\hline \multicolumn{7}{|l|}{ Human capital variables } \\
\hline $\begin{array}{l}\text { Percentage population } 18 \text { years and over: some college or higher degree } \\
\end{array}$ & & & $\begin{array}{l}0.0016 * * \\
(0.0008)\end{array}$ & & & $\begin{array}{l}0.0014^{*} \\
(0.0008)\end{array}$ \\
\hline Percentage population 18 years and over: high school graduate or higher degree & & & $\begin{array}{c}0.0012 \\
(0.0007) \\
\end{array}$ & & & $\begin{array}{l}0.0016^{*} \\
(0.0007) \\
\end{array}$ \\
\hline \multicolumn{7}{|l|}{ Productive structure variables } \\
\hline Unemployment rate & & & $\begin{array}{c}1.40 \mathrm{e}-08 \\
(1.98 \mathrm{e}-07)\end{array}$ & & & $\begin{array}{c}1.71 \mathrm{e}-07 \\
(2.02 \mathrm{e}-07)\end{array}$ \\
\hline \multicolumn{7}{|l|}{ Percentage employed civilian population 16 years and over: } \\
\hline Agriculture, forestry, fishing, and mining & & & $\begin{array}{c}-0.0032 * * \\
(0.0012)\end{array}$ & & & $\begin{array}{c}-0.0021^{*} \\
(0.0013)\end{array}$ \\
\hline Construction & & & $\begin{array}{c}-0.0088^{* * *} \\
(0.0017)\end{array}$ & & & $\begin{array}{c}-0.0075^{* * *} \\
(0.0018)\end{array}$ \\
\hline Manufacturing (durable and nondurable goods) & & & $\begin{array}{c}-0.0008 \\
(0.0007)\end{array}$ & & & $\begin{array}{c}-0.0014^{*} \\
(0.0007)\end{array}$ \\
\hline Wholesale and Retail trade & & & $\begin{array}{c}-0.0048 * * * \\
(0.0011)\end{array}$ & & & $\begin{array}{c}-0.0047^{* * * *} \\
(0.0012)\end{array}$ \\
\hline Finance, insurance, and real estate & & & $\begin{array}{c}0.0013 \\
(0.0016)\end{array}$ & & & $\begin{array}{c}0.0008 \\
(0.0016)\end{array}$ \\
\hline Educational, health, and other professional and related services & & & $\begin{array}{c}-0.0036^{* * * *} \\
(0.0008)\end{array}$ & & & $\begin{array}{c}-0.0036^{* * * *} \\
(0.0008)\end{array}$ \\
\hline Public administration & & & $\begin{array}{c}-0.0036^{* * *} \\
(0.0010) \\
\end{array}$ & & & $\begin{array}{c}-0.0033^{* * * *} \\
(0.0010) \\
\end{array}$ \\
\hline \multicolumn{7}{|l|}{ Weather } \\
\hline Temperature index & & $\begin{array}{c}-0.0032^{* * *} \\
(0.0004)\end{array}$ & $\begin{array}{c}-0.0022 * * * \\
(0.0004)\end{array}$ & & $\begin{array}{c}-0.0036^{* * * *} \\
(0.0004)\end{array}$ & $\begin{array}{c}-0.0029 * * * \\
(0.0004)\end{array}$ \\
\hline Annual precipitation (inches) & & $\begin{array}{c}0.0008 * * * \\
(0.0003)\end{array}$ & $\begin{array}{l}0.0005^{*} \\
(0.0003)\end{array}$ & & $\begin{array}{c}0.0009 * * * \\
(0.0003)\end{array}$ & $\begin{array}{c}0.0009 * * * \\
(0.0002)\end{array}$ \\
\hline Percentage of water area & & $\begin{array}{c}0.0352 * * * \\
(0.0075) \\
\end{array}$ & $\begin{array}{c}0.0323 * * * \\
(0.0073) \\
\end{array}$ & & $\begin{array}{c}0.4016 * * * \\
(0.0076) \\
\end{array}$ & $\begin{array}{c}0.0386 * * * \\
(0.0074) \\
\end{array}$ \\
\hline Regional dummies & No & Yes & Yes & No & Yes & Yes \\
\hline \multirow[t]{2}{*}{$\lambda$} & $-0.0003 * * *$ & $-0.0002 * * *$ & $-0.0001 * * *$ & & & \\
\hline & $(0.0000)$ & $(0.0000)$ & $(0.0000)$ & & & \\
\hline \multirow[t]{2}{*}{$\rho$} & & & & $-0.0007 * * *$ & -0.0001 & -0.0002 \\
\hline & & & & $(0.0000)$ & $(0.0000)$ & $(0.0000)$ \\
\hline Wald test of $\lambda$ or $\rho=0$ & 60.228 & 19.725 & 33.046 & 49.358 & 0.788 & 2.491 \\
\hline Log likelihood & 1123.2568 & 1255.5684 & 1303.3859 & 1083.6497 & 1241.3496 & 1278.4929 \\
\hline
\end{tabular}

Note: Dependent variable: Per-Capita Income growth 1989-1999 (ln scale). Significant at the *** 1\% level, ** 5\% level, * $10 \%$ level. 
Table 4. Population growth models

\begin{tabular}{|c|c|c|c|c|c|c|}
\hline \multirow[b]{2}{*}{ Variables } & \multicolumn{3}{|c|}{ Spatial error models } & \multicolumn{3}{|c|}{ Spatial lag models } \\
\hline & $(1)$ & $(2)$ & (3) & (4) & (5) & (6) \\
\hline Population in 1990 (ln scale) $\leq u$ & $\begin{array}{c}-0.1324 * * * \\
(0.0106)\end{array}$ & $\begin{array}{c}-0.0754 * * * \\
(0.0088)\end{array}$ & $\begin{array}{c}-0.0765^{* * *} \\
(0.0091)\end{array}$ & $\begin{array}{c}-0.1349 * * * \\
(0.0104)\end{array}$ & $\begin{array}{c}-0.0685^{* * * *} \\
(0.0088)\end{array}$ & $\begin{array}{c}-0.0711 * * * \\
(0.0091)\end{array}$ \\
\hline Population in 1990 (ln scale) $>u$ & $\begin{array}{c}-0.1171^{* * *} \\
(0.0092)\end{array}$ & $\begin{array}{c}-0.0668^{* * *} * \\
(0.0077)\end{array}$ & $\begin{array}{c}-0.0691 * * * \\
(0.0081) \\
\end{array}$ & $\begin{array}{c}-0.1188^{* * *} * \\
(0.0089)\end{array}$ & $\begin{array}{c}-0.0598^{* * *} \\
(0.0076)\end{array}$ & $\begin{array}{c}-0.0635 * * * \\
(0.0081) \\
\end{array}$ \\
\hline \multicolumn{7}{|l|}{ Urban sprawl } \\
\hline Land Area Growth (In scale) & & $\begin{array}{c}0.4696 * * * \\
(0.0342)\end{array}$ & $\begin{array}{c}0.4605 * * * \\
(0.0322)\end{array}$ & & $\begin{array}{c}0.5125^{* * * *} \\
(0.0331)\end{array}$ & $\begin{array}{c}0.4951^{* * * *} \\
(0.0315)\end{array}$ \\
\hline Population per Square Mile (ln scale) & & $\begin{array}{c}-0.0775 * * * \\
(0.0072)\end{array}$ & $\begin{array}{c}-0.0640 * * * \\
(0.0072)\end{array}$ & & $\begin{array}{c}-0.0916^{* * * *} \\
(0.0067)\end{array}$ & $\begin{array}{c}-0.0761 * * * \\
(0.0067)\end{array}$ \\
\hline Median Travel Time to Work (in minutes) & & $\begin{array}{c}0.0144^{* * * *} \\
(0.0011)\end{array}$ & $\begin{array}{c}0.0082^{* * * *} \\
(0.0013)\end{array}$ & & $\begin{array}{c}0.0100^{* * * *} \\
(0.0011)\end{array}$ & $\begin{array}{c}0.0050 * * * \\
(0.0012) \\
\end{array}$ \\
\hline \multicolumn{7}{|l|}{ Human capital variables } \\
\hline Percentage population 18 years and over: some college or higher degree & & & $\begin{array}{c}0.0085^{* * * *} \\
(0013)\end{array}$ & & & $\begin{array}{c}0.0075^{* * *} \\
(0.0013)\end{array}$ \\
\hline Percentage population 18 years and over: high school graduate or higher degree & & & $\begin{array}{c}-0.0057 * * * \\
(0.0011) \\
\end{array}$ & & & $\begin{array}{c}-0.0046 * * * \\
(0.0011) \\
\end{array}$ \\
\hline \multicolumn{7}{|l|}{ Productive structure variables } \\
\hline Unemployment rate & & & $\begin{array}{c}1.32 \mathrm{e}-06 * * * \\
(3.84 \mathrm{e}-07)\end{array}$ & & & $\begin{array}{r}1.40 \mathrm{e}-06^{* * *} \\
(3.83 \mathrm{e}-07)\end{array}$ \\
\hline \multicolumn{7}{|l|}{ Percentage employed civilian population 16 years and over: } \\
\hline Agriculture, forestry, fishing, and mining & & & $\begin{array}{c}0.0019 \\
(0.0021)\end{array}$ & & & $\begin{array}{c}0.0045^{* *} \\
(0.0021)\end{array}$ \\
\hline Construction & & & $\begin{array}{c}0.0012 \\
(0.0029)\end{array}$ & & & $\begin{array}{c}0.0036 \\
(0.0029)\end{array}$ \\
\hline Manufacturing (durable and nondurable goods) & & & $\begin{array}{c}-0.0042^{* * *} \\
(0.0012)\end{array}$ & & & $\begin{array}{c}-0.0044 * * * \\
(0.0012)\end{array}$ \\
\hline Wholesale and Retail trade & & & $\begin{array}{c}-0.0058^{* * * *} \\
(0.0020)\end{array}$ & & & $\begin{array}{c}-0.0054 * * * \\
(0.0019)\end{array}$ \\
\hline Finance, insurance, and real estate & & & $\begin{array}{l}-0.0023 \\
(0.0025)\end{array}$ & & & $\begin{array}{l}-0.0031 \\
(0.0025)\end{array}$ \\
\hline Educational, health, and other professional and related services & & & $\begin{array}{c}-0.0120^{* * *} \\
(0.0013)\end{array}$ & & & $\begin{array}{c}-0.0110 * * * \\
(0.0014)\end{array}$ \\
\hline Public administration & & & $\begin{array}{c}-0.0072^{* * *} \\
(0.0017)\end{array}$ & & & $\begin{array}{c}-0.0059 * * * \\
(0.0017) \\
\end{array}$ \\
\hline \multicolumn{7}{|l|}{ Weather } \\
\hline Temperature index & & $\begin{array}{l}-0.0000 \\
(0.0006)\end{array}$ & $\begin{array}{l}-0.0009 \\
(0.0007)\end{array}$ & & $\begin{array}{l}-0.0011 \\
(0.0007)\end{array}$ & $\begin{array}{c}-0.0021 * * * \\
(0.0007)\end{array}$ \\
\hline Annual precipitation (inches) & & $\begin{array}{c}-0.0015^{* * * *} \\
(0.0005)\end{array}$ & $\begin{array}{l}-0.0007 \\
(0.0005)\end{array}$ & & $\begin{array}{c}-0.0009^{*} \\
(0.0005)\end{array}$ & $\begin{array}{l}-0.0002 \\
(0.0005)\end{array}$ \\
\hline Percentage of water area & & $-0.0287^{* *}$ & $-0.0362^{* * *}$ & & -0.0153 & $-0.0244^{* *}$ \\
\hline Regional dummies & No & Yes & Yes & No & Yes & Yes \\
\hline \multirow[t]{2}{*}{$\lambda$} & $-0.0001^{*}$ & $-0.0001 *$ & $-0.0001^{* * *}$ & & & \\
\hline & $(0.0000)$ & $(0.0000)$ & $(0.0000)$ & & & \\
\hline \multirow[t]{2}{*}{$\rho$} & & & & $0.0031^{* * *}$ & $0.0023 * * *$ & $0.0015^{* * *}$ \\
\hline & & & & $(0.0003)$ & $(0.0004)$ & $(0.0004)$ \\
\hline Wald test of $\lambda$ or $\rho=0$ & 3.772 & 3.480 & 7.058 & 82.914 & 28.948 & 12.569 \\
\hline Log likelihood & 314.2802 & 611.6961 & 693.3034 & 352.3903 & 624.0187 & 695.4746 \\
\hline
\end{tabular}


Table 5. Diagnostics for per-capita income and population models for polynomial model accounting for higher orders

\begin{tabular}{lcccc}
\hline \multicolumn{4}{c}{ Income growth model } & \multicolumn{2}{c}{ Population growth model } \\
\hline Test & Statistic & p-value & Statistic & p-value \\
\hline Spatial error: & & & & \\
$\quad$ Moran's I & 1.313 & 0.189 & 1.149 & 0.251 \\
$\quad$ Lagrange multiplier & 1057.155 & 0.000 & 242.690 & 0.000 \\
$\quad$ Robust Lagrange multiplier & 1124.464 & 0.000 & 277.952 & 0.000 \\
\hline Spatial lag: & & & & \\
$\quad$ Lagrange multiplier & 20.608 & 0.000 & 1.924 & 0.165 \\
$\quad$ Robust Lagrange multiplier & 87.917 & 0.000 & 37.186 & 0.000 \\
\hline
\end{tabular}

Note: The null hypothesis in all tests is that there is zero spatial autocorrelation. 
Table 6. Robustness analysis: polynomial model for per-capita income growth

\begin{tabular}{|c|c|c|c|c|c|c|}
\hline \multirow[b]{2}{*}{ Variables } & \multicolumn{3}{|c|}{ Spatial error models } & \multicolumn{3}{|c|}{ Spatial lag models } \\
\hline & $(1)$ & $(2)$ & (3) & (4) & (5) & (6) \\
\hline Per-Capita Income (ln scale) in 1989 & $\begin{array}{l}-56.720^{* * *} \\
(0.5584)\end{array}$ & $\begin{array}{c}-61.797^{* * *} \\
(0.4631)\end{array}$ & $\begin{array}{l}-59.650^{* * *} \\
(0.3866)\end{array}$ & $\begin{array}{c}-47.037^{* * *} \\
(8.5703)\end{array}$ & $\begin{array}{l}-60.265^{* * *} \\
(7.5814)\end{array}$ & $\begin{array}{c}-58.541 * * * \\
(7.262)\end{array}$ \\
\hline Per-Capita Income (In scale) in 1989 to power 2 & $\begin{array}{c}5.7518^{* * *} \\
(0.0661)\end{array}$ & $\begin{array}{c}6.2658^{* * *} \\
(0.4599)\end{array}$ & $\begin{array}{c}6.0300 * * * \\
(0.0397)\end{array}$ & $\begin{array}{c}4.7722 * * * \\
(0.8825)\end{array}$ & $\begin{array}{c}6.1152^{* * * *} \\
(0.7808)\end{array}$ & $\begin{array}{c}6.0252^{* * * *} \\
(0.0942)\end{array}$ \\
\hline Per-Capita Income (ln scale) in 1989 to power 3 & $\begin{array}{c}-0.1939 * * * \\
(0.0026)\end{array}$ & $\begin{array}{c}-0.2112^{* * *} \\
(0.0017)\end{array}$ & $\begin{array}{c}-0.2029^{* * *} \\
(0.0016)\end{array}$ & $\begin{array}{c}-0.1610^{* * *} \\
(0.0302)\end{array}$ & $\begin{array}{c}-0.2064 * * * \\
(0.0267)\end{array}$ & $\begin{array}{c}-0.2031 * * * * \\
(0.0004)\end{array}$ \\
\hline \multicolumn{7}{|l|}{ Urban sprawl } \\
\hline Land Area Growth (ln scale) & & $\begin{array}{l}0.0494 * * \\
(0.0203)\end{array}$ & $\begin{array}{c}0.0556^{* * *} \\
(0.0196)\end{array}$ & & $\begin{array}{c}0.0685^{* * *} \\
(0.0210)\end{array}$ & $\begin{array}{c}0.0745^{* * *} \\
(0.0118)\end{array}$ \\
\hline Population per Square Mile (ln scale) & & $\begin{array}{l}-0.0024 \\
(0.0040)\end{array}$ & $\begin{array}{c}-0.0098^{* * *} \\
(0.0040)\end{array}$ & & $\begin{array}{c}-0.0092 * * \\
(0.0042)\end{array}$ & $\begin{array}{c}-0.0088^{* * *} \\
(0.0034)\end{array}$ \\
\hline Median Travel Time to Work (in minutes) & & $\begin{array}{c}-0.0002 \\
(0.0006)\end{array}$ & $\begin{array}{l}0.0015^{*} \\
(0.0007)\end{array}$ & & $\begin{array}{c}-0.0014 * * \\
(0.0007)\end{array}$ & $\begin{array}{c}-0.0011^{*} \\
(0.0006)\end{array}$ \\
\hline \multicolumn{7}{|l|}{ Human capital variables } \\
\hline Percentage population 18 years and over: some college or higher degree & & & $\begin{array}{l}0.0021^{*} \\
(0.0008)\end{array}$ & & & $\begin{array}{l}0.0017^{*} \\
(0.0007)\end{array}$ \\
\hline Percentage population 18 years and over: high school graduate or higher degree & & & $\begin{array}{l}-0.0000 \\
(0.0007)\end{array}$ & & & $\begin{array}{l}0.0009^{*} \\
(0.0005)\end{array}$ \\
\hline \multicolumn{7}{|l|}{ Productive structure variables } \\
\hline Unemployment rate & & & $\begin{array}{c}1.36 \mathrm{e}-07 \\
(1.75 \mathrm{e}-07)\end{array}$ & & & $\begin{array}{c}1.83 \mathrm{e}-07 \\
(1.98 \mathrm{e}-07)\end{array}$ \\
\hline $\begin{array}{l}\text { Percentage employed civilian population } 16 \text { years and over: } \\
\text { Agriculture, forestry, fishing, and mining }\end{array}$ & & & $\begin{array}{c}-0.0060 * * \\
(0.0013)\end{array}$ & & & $\begin{array}{c}-0.0042 * * \\
(0.0023)\end{array}$ \\
\hline Construction & & & $\begin{array}{c}-0.0075^{* * *} \\
(0.0017)\end{array}$ & & & $\begin{array}{c}-0.0073 * * * \\
(0.0020)\end{array}$ \\
\hline Manufacturing (durable and nondurable goods) & & & $\begin{array}{c}0.0003 \\
(0.0007)\end{array}$ & & & $\begin{array}{c}0.0006 \\
(0.0010)\end{array}$ \\
\hline Wholesale and Retail trade & & & $\begin{array}{c}-0.0029 * * \\
(0.0011)\end{array}$ & & & $\begin{array}{c}-0.0050^{* * *} \\
(0.0020)\end{array}$ \\
\hline Finance, insurance, and real estate & & & $\begin{array}{c}0.0008 \\
(0.0015)\end{array}$ & & & $\begin{array}{c}0.0010 \\
(0.0017)\end{array}$ \\
\hline Educational, health, and other professional and related services & & & $\begin{array}{l}-0.0014^{*} \\
(0.0008)\end{array}$ & & & $\begin{array}{c}-0.0022 * * * \\
(0.0012)\end{array}$ \\
\hline Public administration & & & $\begin{array}{c}-0.0026^{* * *} \\
(0.0009)\end{array}$ & & & $\begin{array}{c}-0.0029 * * * \\
(0.0013)\end{array}$ \\
\hline \multicolumn{7}{|l|}{ Weather } \\
\hline Temperature index & & $\begin{array}{c}-0.0027^{* * *} \\
(0.0004)\end{array}$ & $\begin{array}{c}-0.0017^{* * *} \\
(0.0004)\end{array}$ & & $\begin{array}{c}-0.0036^{* * * *} \\
(0.0004)\end{array}$ & $\begin{array}{c}-0.0020^{* * * *} \\
(0.0004)\end{array}$ \\
\hline Annual precipitation (inches) & & $\begin{array}{c}0.0009 * * * \\
(0.0003)\end{array}$ & $\begin{array}{l}0.0005^{*} \\
(0.0002)\end{array}$ & & $\begin{array}{c}0.0013^{* * * *} \\
(0.0003)\end{array}$ & $\begin{array}{c}0.0009 * * * \\
(0.0004)\end{array}$ \\
\hline Percentage of water area & & $\begin{array}{c}0.0322 * * * \\
(0.0068)\end{array}$ & $\begin{array}{c}0.0299 * * * \\
(0.0065)\end{array}$ & & $\begin{array}{c}0.0400 * * * \\
(0.0070)\end{array}$ & $\begin{array}{c}0.0306 * * * \\
(0.0035)\end{array}$ \\
\hline Regional dummies & No & Yes & Yes & No & Yes & Yes \\
\hline \multirow[t]{2}{*}{$\lambda$} & $0.0003^{* * * *}$ & $0.0000^{* * * *}$ & $0.0000^{* * * *}$ & & & \\
\hline & $(0.0000)$ & $(0.0000)$ & $(0.0000)$ & & & \\
\hline \multirow[t]{2}{*}{$\rho$} & & & & $-0.0010^{* * *}$ & -0.0005 & 0.0000 \\
\hline & & & & $(0.0000)$ & $(0.0000)$ & $(0.0000)$ \\
\hline Wald test of $\lambda$ or $\rho=0$ & 318.647 & 86.784 & 121.071 & 117.967 & 17.906 & 114.288 \\
\hline Log likelihood & 1137.0772 & 1234.052 & 1284.927 & 1055.958 & 1201.407 & 1256.924 \\
\hline
\end{tabular}

Note: Dependent variable: Per-Capita Income growth 1989-1999 (ln scale). Significant at the *** 1\% level, ** 5\% level, * $10 \%$ level. 
Table 7. Diagnostics for per-capita income and population models for model accounting for interactions

\begin{tabular}{lcccc}
\hline & \multicolumn{2}{c}{ Income growth model } & \multicolumn{2}{c}{ Population growth model } \\
\hline Test & Statistic & p-value & Statistic & p-value \\
\hline Spatial error: & & & & \\
$\quad$ Moran's I & 1.494 & 0.135 & 1.157 & 0.247 \\
$\quad$ Lagrange multiplier & 696.728 & 0.000 & 230.749 & 0.000 \\
$\quad$ Robust Lagrange multiplier & 744.901 & 0.000 & 265.963 & 0.000 \\
\hline Spatial lag: & & & & \\
$\quad$ Lagrange multiplier & 16.444 & 0.000 & 1.466 & 0.226 \\
$\quad$ Robust Lagrange multiplier & 64.617 & 0.000 & 36.680 & 0.000 \\
\hline
\end{tabular}

Note: The null hypothesis in all tests is that there is zero spatial autocorrelation. 
Table 8. Robustness analysis: interaction effects model for per-capita income growth

\begin{tabular}{|c|c|c|c|c|c|c|}
\hline \multirow[b]{2}{*}{ Variables } & \multicolumn{3}{|c|}{ Spatial error models } & \multicolumn{3}{|c|}{ Spatial lag models } \\
\hline & $(1)$ & $(2)$ & $(3)$ & $(4)$ & $(5)$ & $(6)$ \\
\hline Per-Capita Income (ln scale) in 1989 & $\begin{array}{c}-0.0253 * * * \\
(0.0055)\end{array}$ & $\begin{array}{c}-0 . .2958 * * * \\
(0.0942)\end{array}$ & $\begin{array}{c}-0.6863 \\
(0.2346) \\
\end{array}$ & $\begin{array}{c}0.0256^{* *} \\
(0.0101) \\
\end{array}$ & $\begin{array}{c}-0.2596 * * \\
(0.1203) \\
\end{array}$ & $\begin{array}{l}-0.4830^{*} \\
(0.2766) \\
\end{array}$ \\
\hline \multicolumn{7}{|l|}{ Urban sprawl } \\
\hline Land Area Growth (ln scale) & & $\begin{array}{c}1.8274 * * \\
(0.7407)\end{array}$ & $\begin{array}{c}1.3963^{* *} \\
(0.7084)\end{array}$ & & $\begin{array}{c}1.9583^{* *} \\
(0.7655)\end{array}$ & $\begin{array}{l}1.3428^{*} \\
(0.7330)\end{array}$ \\
\hline Land Area Growth (ln scale) *int & & $\begin{array}{c}-0.1874 * * \\
(0.0780)\end{array}$ & $\begin{array}{l}-0.1412^{*} \\
(0.0746)\end{array}$ & & $\begin{array}{c}-0.1992 \\
(0.0807)\end{array}$ & $\begin{array}{c}-0.1339^{*} \\
(0.0772)\end{array}$ \\
\hline Population per Square Mile (ln scale) & & $\begin{array}{c}-0.2742^{* *} \\
(0.1082)\end{array}$ & $\begin{array}{l}-0.5385 \\
(0.1263)\end{array}$ & & $\begin{array}{l}-0.2406^{*} \\
(0.1244)\end{array}$ & $\begin{array}{c}-0.5185 * * * \\
(0.1328)\end{array}$ \\
\hline Population per Square Mile (ln scale) *int & & $\begin{array}{c}-0.0193^{* *} \\
(0.0039)\end{array}$ & $\begin{array}{c}0.0546 * * * \\
(0.0132)\end{array}$ & & $\begin{array}{c}0.0240 * * \\
(0.0129)\end{array}$ & $\begin{array}{c}0.0519 * * * \\
(0.0138)\end{array}$ \\
\hline Median Travel Time to Work (in minutes) & & $\begin{array}{l}-0.0065 \\
(0.0196)\end{array}$ & $\begin{array}{c}0.0203 \\
(0.0243)\end{array}$ & & $\begin{array}{c}-0.0098 \\
(0.0202)\end{array}$ & $\begin{array}{c}0.0200 \\
(0.0253)\end{array}$ \\
\hline Median Travel Time to Work (in minutes) *int & & $\begin{array}{c}0.0007 \\
(0.0020) \\
\end{array}$ & $\begin{array}{c}-0.0018 \\
(0.0025) \\
\end{array}$ & & $\begin{array}{c}0.0010 \\
(0.0021) \\
\end{array}$ & $\begin{array}{c}-0.0019 \\
(0.0026) \\
\end{array}$ \\
\hline \multicolumn{7}{|l|}{ Human capital variables } \\
\hline Percentage population 18 years and over: some college or higher degree & & & $\begin{array}{c}-0.0638 * * * \\
(0.0213)\end{array}$ & & & $\begin{array}{c}-0.0464 * * \\
(0.0224)\end{array}$ \\
\hline Percentage population 18 years and over: some college or higher degree*int & & & $\begin{array}{c}0.0068 * * * \\
(0.0022)\end{array}$ & & & $\begin{array}{c}0.0051^{* *} \\
(0.0023)\end{array}$ \\
\hline Percentage population 18 years and over: high school graduate or higher degree & & & $\begin{array}{l}-0.0244 \\
(0.0202)\end{array}$ & & & $\begin{array}{c}-0.0448 * * \\
(0.0210)\end{array}$ \\
\hline Percentage population 18 years and over: high school graduate or higher degree*int & & & $\begin{array}{c}0.0027 \\
(0.0021) \\
\end{array}$ & & & $\begin{array}{l}0.0048 * * \\
(0.0022) \\
\end{array}$ \\
\hline \multicolumn{7}{|l|}{ Productive structure variables } \\
\hline Unemployment rate & & & $\begin{array}{c}5.66 \mathrm{e}-06 \\
(0.0000)\end{array}$ & & & $\begin{array}{c}0.0000 \\
(0.0000)\end{array}$ \\
\hline Unemployment rate & & & $\begin{array}{l}-5.74 \mathrm{e}-07 \\
(1.14 \mathrm{e}-06)\end{array}$ & & & $\begin{array}{c}-1.06 e-06 \\
(1.17 e-06)\end{array}$ \\
\hline \multicolumn{7}{|l|}{ Percentage employed civilian population 16 years and over: } \\
\hline Agriculture, forestry, fishing, and mining & & & $\begin{array}{c}0.0064 \\
(0.0524)\end{array}$ & & & $\begin{array}{c}0.0248 \\
(0.0549)\end{array}$ \\
\hline Agriculture, forestry, fishing, and mining*int & & & $\begin{array}{l}-0.0012 \\
(0.0055)\end{array}$ & & & $\begin{array}{c}-0.0030 \\
(0.0058)\end{array}$ \\
\hline Construction & & & $\begin{array}{c}-0.1957 * * * \\
(0.6051)\end{array}$ & & & $\begin{array}{c}-0.1876^{* * *} \\
(0.0631)\end{array}$ \\
\hline Construction*int & & & $\begin{array}{c}0.0198 * * \\
(0.0063)\end{array}$ & & & $\begin{array}{c}0.0191 * * \\
(0.0066)\end{array}$ \\
\hline Manufacturing (durable and nondurable goods) & & & $\begin{array}{c}0.0086 \\
(0.0198)\end{array}$ & & & $\begin{array}{c}0.0166 \\
(0.0218)\end{array}$ \\
\hline Manufacturing (durable and nondurable goods)*int & & & $\begin{array}{l}-0.0008 \\
(0.0021)\end{array}$ & & & $\begin{array}{l}-0.0017 \\
(0.0023)\end{array}$ \\
\hline Wholesale and Retail trade & & & $\begin{array}{c}0.0974 * * \\
(0.0316)\end{array}$ & & & $\begin{array}{c}0.1213 * * * \\
(0.0348)\end{array}$ \\
\hline Wholesale and Retail trade*int & & & $\begin{array}{c}-0.0104^{* *} \\
(0.0033)\end{array}$ & & & $\begin{array}{c}-0.0130 * * * \\
(0.0036)\end{array}$ \\
\hline Finance, insurance, and real estate & & & $\begin{array}{c}0.1436 * * * \\
(0.0417)\end{array}$ & & & $\begin{array}{c}0.1805^{* * *} \\
(0.0436)\end{array}$ \\
\hline Finance, insurance, and real estate*int & & & $\begin{array}{c}-0.0147 * * * \\
(0.0043)\end{array}$ & & & $\begin{array}{c}-0.0186^{* * * *} \\
(0.0045)\end{array}$ \\
\hline Educational, health, and other professional and related services & & & $\begin{array}{c}0.0257 \\
(0.0227)\end{array}$ & & & $\begin{array}{l}0.0435^{*} \\
(0.2502)\end{array}$ \\
\hline Educational, health, and other professional and related services*int & & & $\begin{array}{l}-0.0029 \\
(0.0023)\end{array}$ & & & $\begin{array}{l}-0.0048^{*} \\
(0.0026)\end{array}$ \\
\hline Public administration & & & $\begin{array}{c}0.0314 \\
(0.0349)\end{array}$ & & & $\begin{array}{c}0.0534 \\
(0.0374)\end{array}$ \\
\hline Public administration*int & & & $\begin{array}{c}-0.0036 \\
(0.0036) \\
\end{array}$ & & & $\begin{array}{l}-0.0059 \\
(0.0039) \\
\end{array}$ \\
\hline \multicolumn{7}{|l|}{ Weather } \\
\hline Temperature index & & $\begin{array}{c}-0.0185^{* *} \\
(0.0073)\end{array}$ & $\begin{array}{l}-0.0004 \\
(0.0082)\end{array}$ & & $\begin{array}{c}-0.0190 * * \\
(0.0077)\end{array}$ & $\begin{array}{c}-0.0003 \\
(0.0087)\end{array}$ \\
\hline Temperature index*int & & $\begin{array}{c}0.0016^{* *} \\
(0.0007)\end{array}$ & $\begin{array}{l}-0.0001 \\
(0.0008)\end{array}$ & & $\begin{array}{c}0.0016^{* *} \\
(0.0007)\end{array}$ & $\begin{array}{c}-0.0002 \\
(0.0008)\end{array}$ \\
\hline Annual precipitation (inches) & & $\begin{array}{l}0.0105 * \\
(0.0057)\end{array}$ & $\begin{array}{l}-0.0049 \\
(0.0061)\end{array}$ & & $\begin{array}{l}0.0118^{*} \\
(0.0062)\end{array}$ & $\begin{array}{l}-0.0062 \\
(0.0063)\end{array}$ \\
\hline Annual precipitation (inches) $*$ int & & $\begin{array}{l}-0.0010^{*} \\
(0.0006)\end{array}$ & $\begin{array}{c}0.0006 \\
(0.0006)\end{array}$ & & $\begin{array}{l}-0.0011^{*} \\
(0.0006)\end{array}$ & $\begin{array}{c}0.0007 \\
(0.0006)\end{array}$ \\
\hline Percentage of water area & & $\begin{array}{c}0.0362 \\
(0.1928)\end{array}$ & $\begin{array}{c}0.4086^{* *} \\
(0.1790)\end{array}$ & & $\begin{array}{c}0.0986 \\
(0.1973)\end{array}$ & $\begin{array}{c}0.4680^{* *} \\
(0.1849)\end{array}$ \\
\hline Percentage of water area*int & & $\begin{array}{l}-0.0007 \\
(0.0196)\end{array}$ & $\begin{array}{c}-0.0391 * * \\
(0.0182)\end{array}$ & & $\begin{array}{l}-0.0064 \\
(0.0200)\end{array}$ & $\begin{array}{c}-0.0444^{* *} \\
(0.0188)\end{array}$ \\
\hline Regional dummies & No & Yes & Yes & No & Yes & Yes \\
\hline$\lambda$ & $-0.0005^{* * *}$ & $-0.0000 * * *$ & $-0.0001 * * *$ & & & \\
\hline & $(0.0000)$ & $(0.0002)$ & $(0.0000)$ & & & \\
\hline$\rho$ & & & & $-0.0009 * * *$ & -0.0004 & -0.0006 \\
\hline & & & & $(0.0000)$ & $(0.0001)$ & $(0.0000)$ \\
\hline Wald test of $\lambda$ or $\rho=0$ & 58.409 & 10.000 & 8.999 & 87.220 & 8.0660 & 21.518 \\
\hline Log likelihood & 1045.808 & 1194.296 & 1311.958 & 1033.872 & 1172.394 & 1278.457 \\
\hline
\end{tabular}

Note: Dependent variable: Per-Capita Income growth 1989-1999 (ln scale). int represents the interaction between the lagged income and the explanatory variable. Significant at the *** $1 \%$ level, ** 5\% level, * $10 \%$ level. 